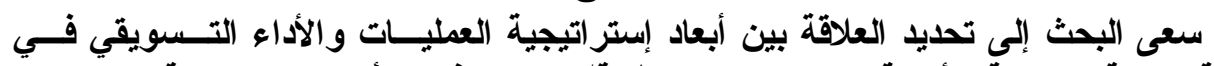

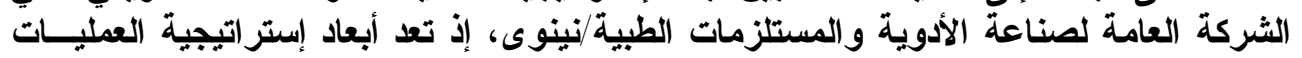

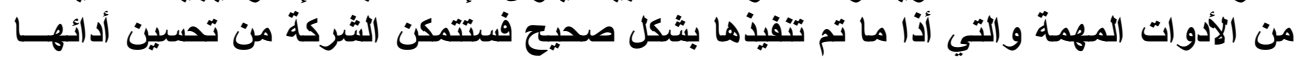

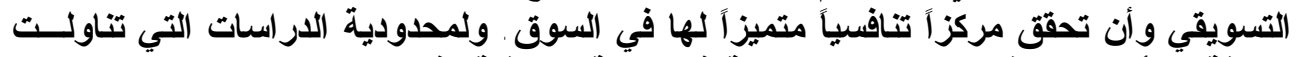

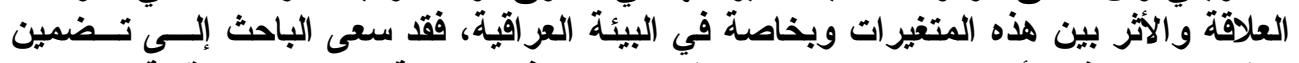

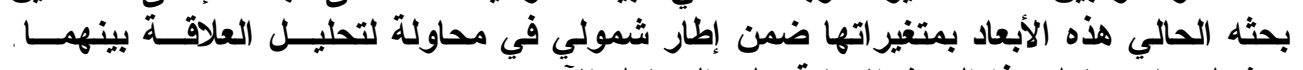

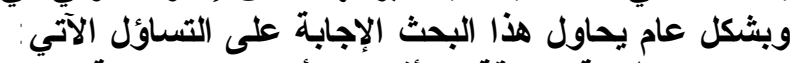

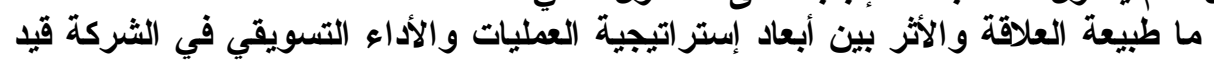
البحث؟

$$
\text { وتوصل البحث إلى مجموعة من الاستنتاجات أهمها: }
$$

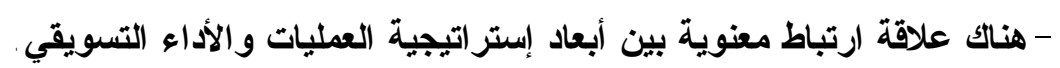

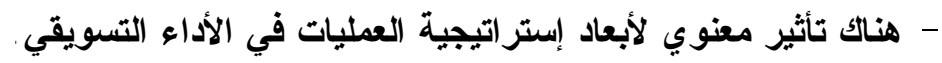

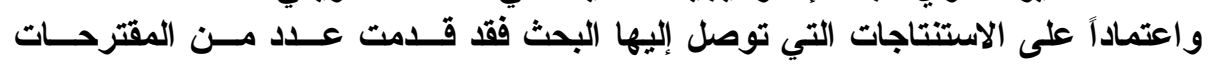
المنسجمة مع هذه الاستنتاجات الاستئات 


\title{
The Relationship between the Dimensions of Operations Strategy and the Marketing Performance: A Pilot Study for the Managers' Opinions in State Company for Drugs Industry and Medical Appliances in Nineveh
}

\author{
Ghanim M. Ahmed \\ Assistant Lecturer \\ Department of Industrial Management \\ University of Mosul
}

\begin{abstract}
The research sought to determine the relationship between the Dimensions of operations strategy and the marketing performance in State Company for Drugs Industry and Medical Appliances in Nineveh, The dimensions of operations strategy from important tools were considered. Through the right Implementation, the company can improve marketing performance and achieve distinctive competitive position in marketplace. Studies have seldom been subjected to deal with relationship and effect of these variables and especially in the Iraqi environment. The present research included these dimensions with their variables in terms of total framework as an attempt to analyze the relationship between them. Generally, the research also tries to answer the following inquiry: What is the nature of the relationship and effect between the dimensions of operations strategy and the marketing performance of the company under research? The research has reached to a set of conclusions and the most important ones are:

- There is a significant relationship between the dimensions of operations strategy and the marketing performance.

- There is a significant effect of the dimensions of operations strategy in the marketing performance.

Depending on the conclusions, a set of harmonized suggestions with these conclusions have been presented in this study.

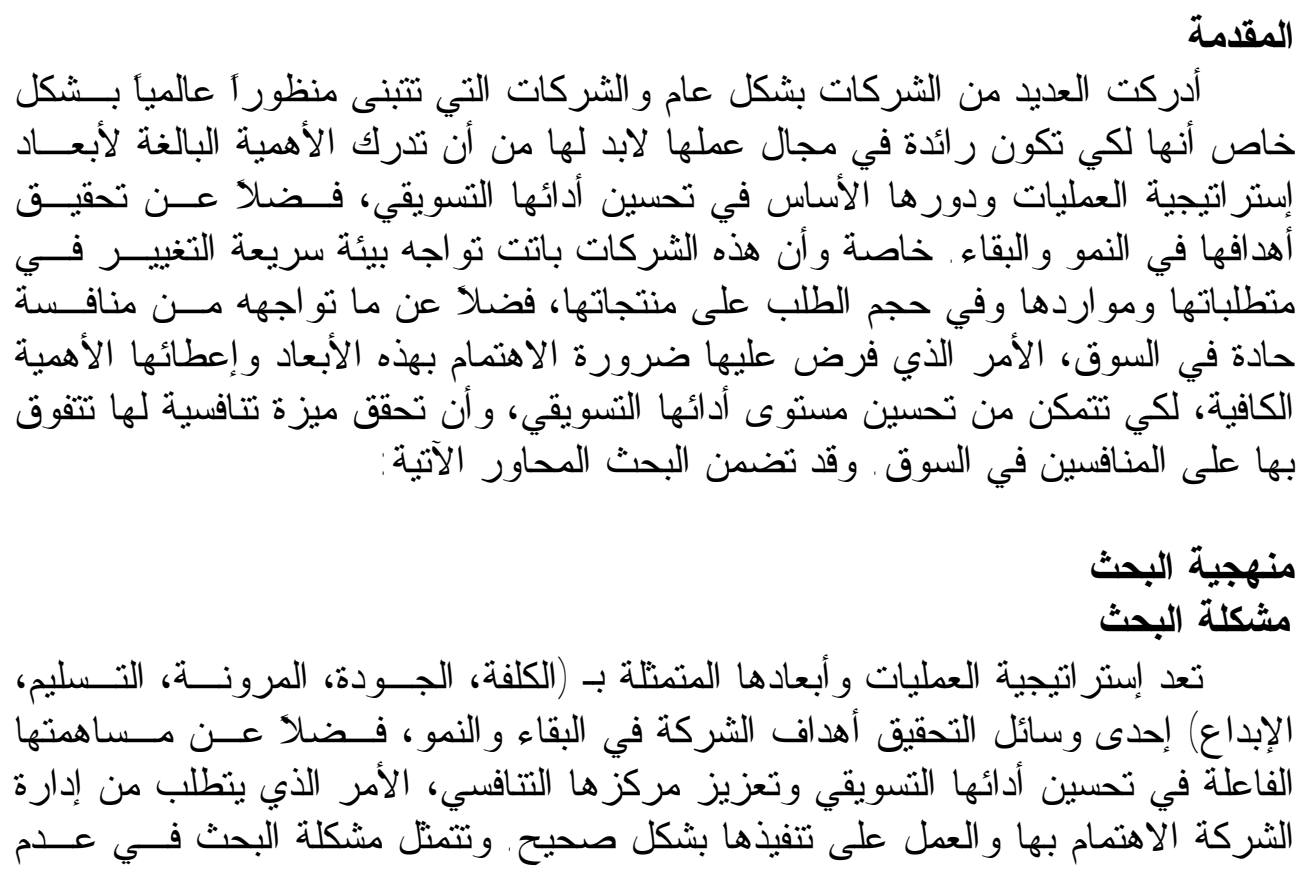




\section{الكيكي[rren}

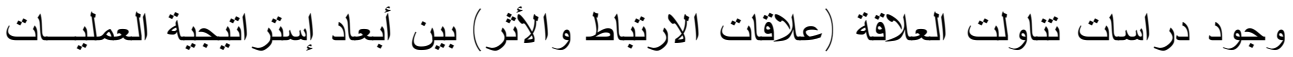

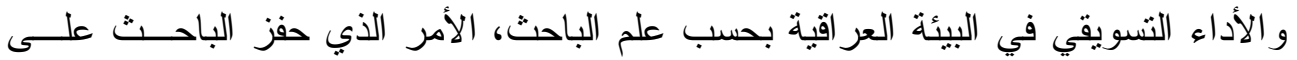

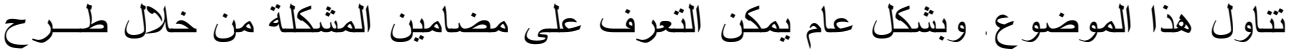
ما طبيعة العلاقة و الأثر بين أبعاد إستر اتيجية العمليــات و الأداء التـسويقي فــي

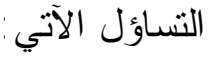
الثركة قيد البحث؟ ملثة

$$
\text { أهداف البحث في ضوء مشكلة البحث يمكن تحديد أهداف البحث بالآتي: }
$$

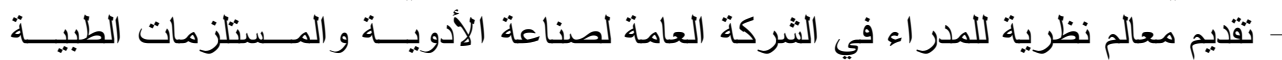

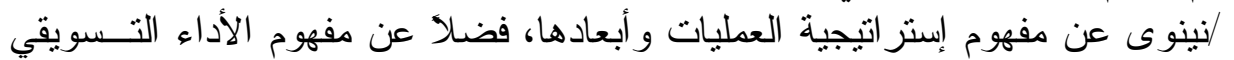

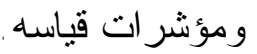

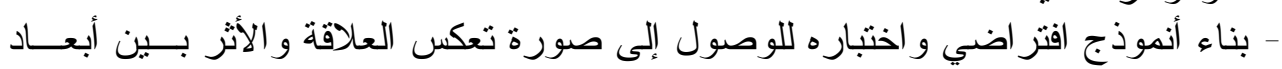

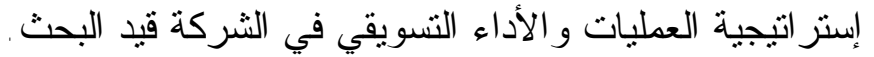

تم تصميم أنموذج افتز اضي وكما في الثكل ا و والذي يثير إلى العلاقة بين أبعـاد

$$
\text { أنموذج البحث }
$$
إستر اتيجية العمليات و الأداء التسويقي في الثركة قيد البحث التئ.

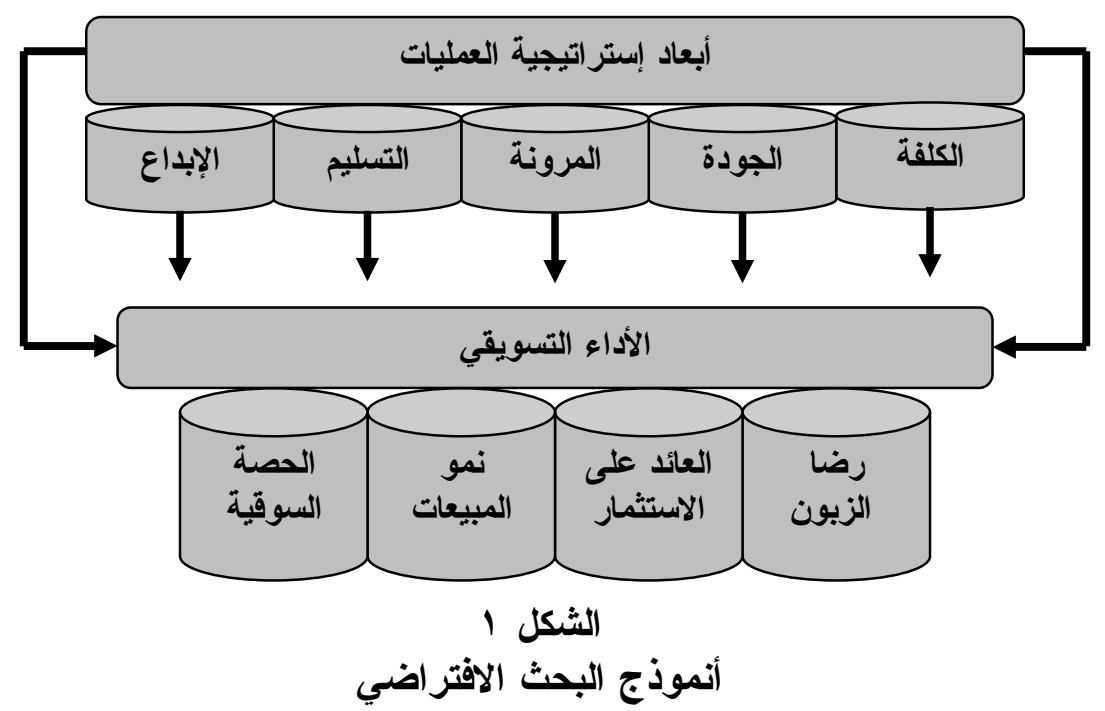

فرضيات البحث الفرضية الرئيسة الأولى : توجد علاقة ارتباط معنوية بين أبعـاد إبــنز اتيجية العمليـات

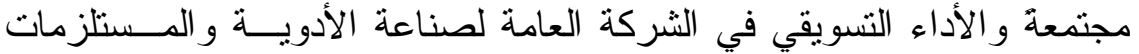

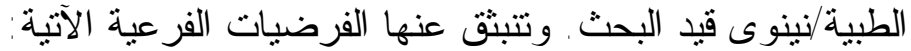




$$
\begin{aligned}
& 1 \text { ـ نوجد علاقة ارتباط معنوية بين بعد الكلفة و الأداء التسويقي . }
\end{aligned}
$$

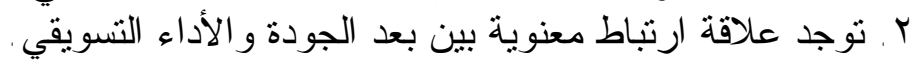

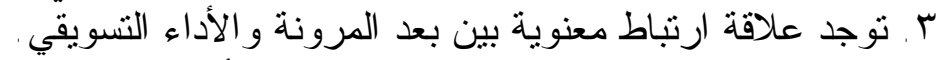

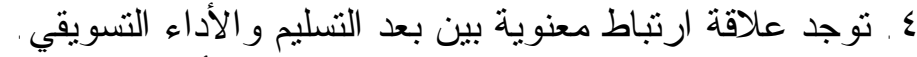

$$
\begin{aligned}
& \text { 0. توجد علاقة ارتباط معنوية بين بعد الإبداع و والأداء التسويقي. }
\end{aligned}
$$

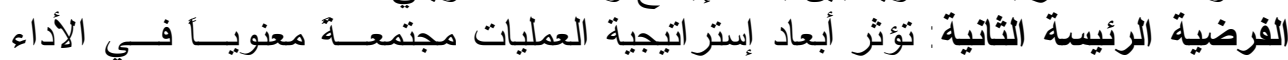

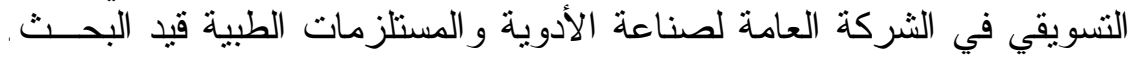

$$
\begin{aligned}
& \text { وتتبثق عنها الفرضيات الفرعية الآتية: } \\
& \text { 1. بوئثر بعد الكلفة معنوياً في الأداء التسويقي. } \\
& \text { r. ب. يؤثر بعد الجودة معنويأ في الأداء التسويقي. } \\
& \text { r. ب. يؤثر بعد المرونة معنوياً في الأداء التسويقي. } \\
& \text { ع. . يؤثر بعد التسليم معنويأ في الأداء التنسويقي. } \\
& \text { ه. يؤثر بعد الإبداع معنويأ في الأداء التسويقي. }
\end{aligned}
$$

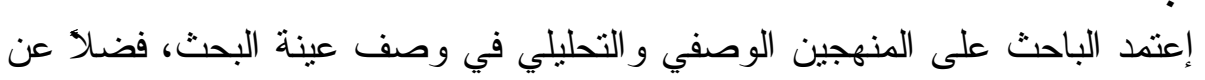

$$
\text { منهج البحث }
$$

دراسة وتحليل العلاقة بين المتغير ات الرئيسة و الفرعية المعتدة في البحثث.

\section{أساليب جمع البيانات في البات}

إعتمد الباحث في جمع البيانات التي تساعده في الوصول إلى نتــائج واســتنتاجات

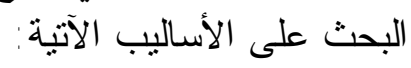

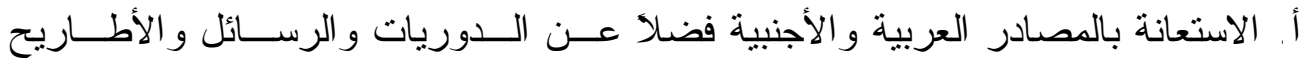

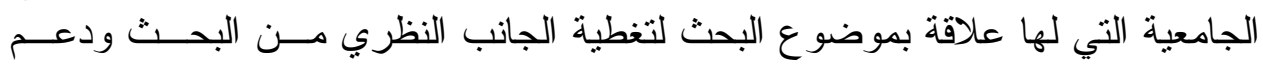

$$
\text { الجانب الميداني بها. }
$$

ب. استمارة الاستبانه " للحصول على بيانات تتعلق بالجانب الميداني، إذ نم إعداد الاستبانة

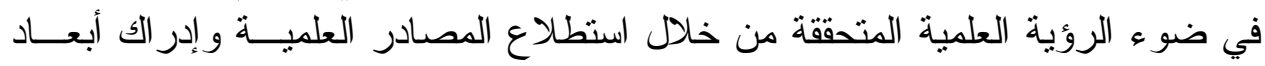

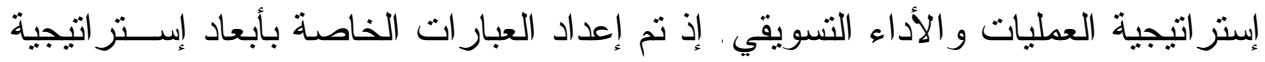

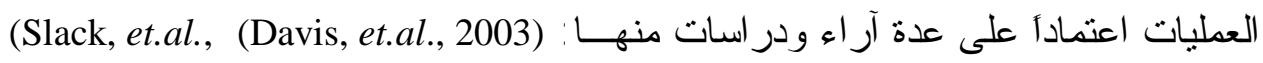

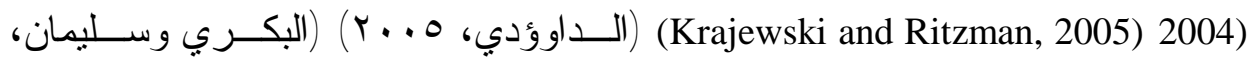

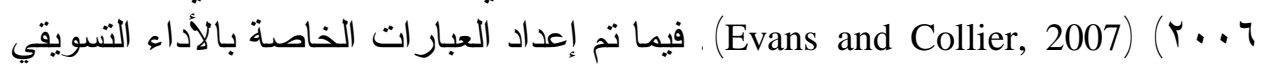

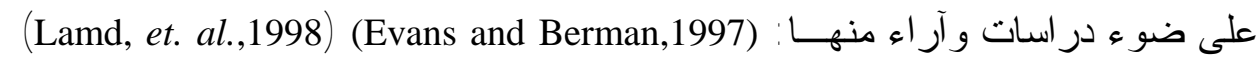

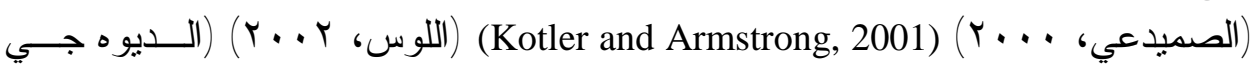




\section{الجاتب النظري

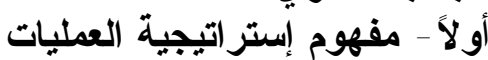

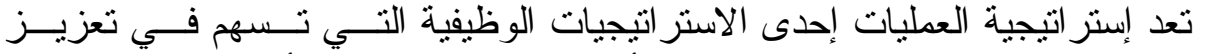

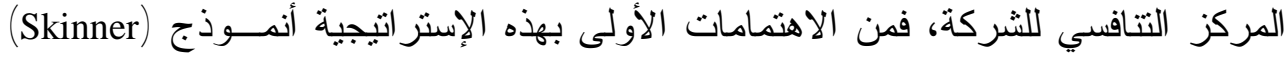

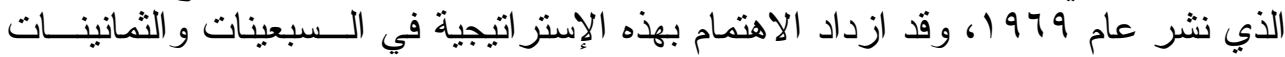

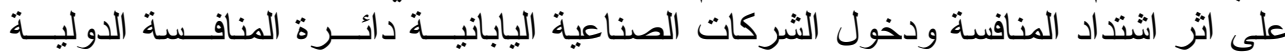

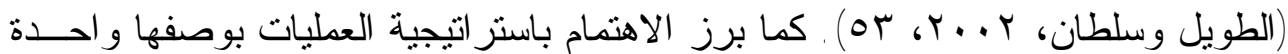

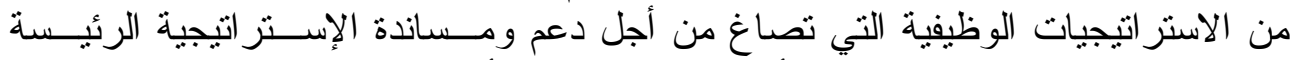

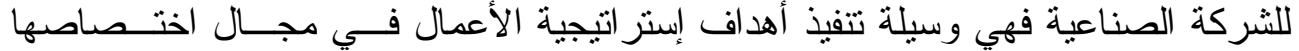

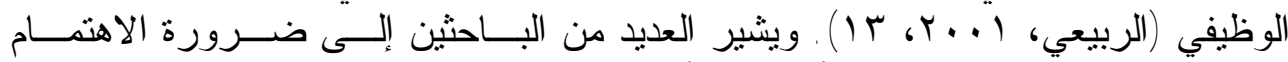

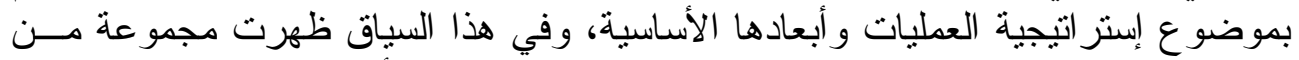
المفاهيم المتعلقة بإستر اتيجية العمليات باعتبار ها وسيلة تتفيذ الأهداف الإستر اتيجية، فيرى الإنية

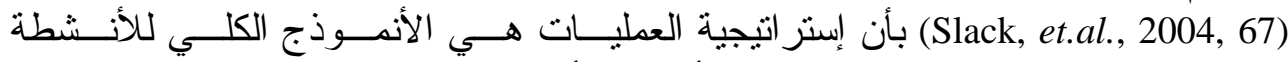

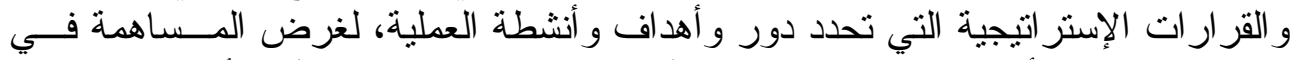

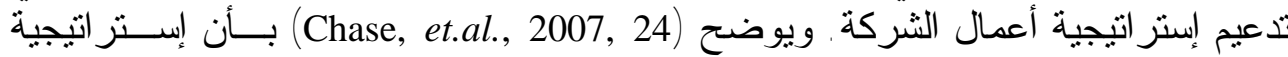

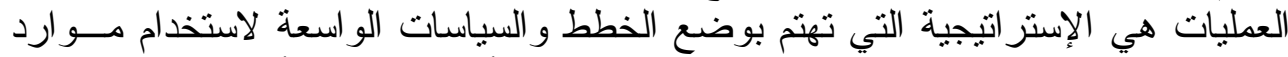

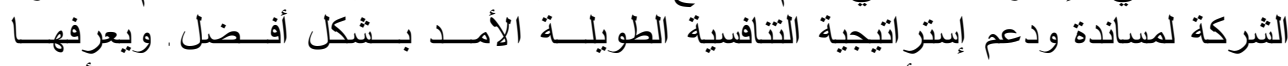
(Schroeder ,2007, 19)

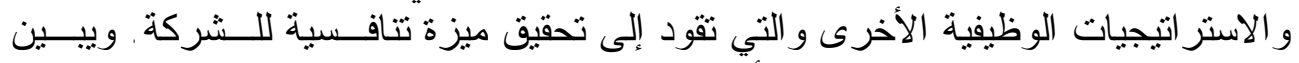
(Evans and Collier, 2007, 133)

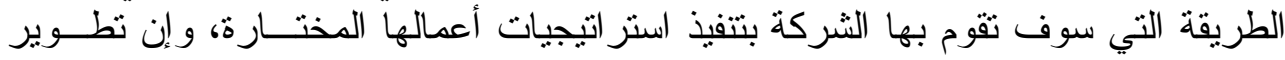

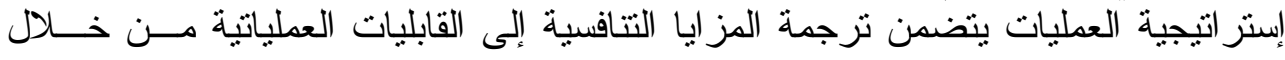

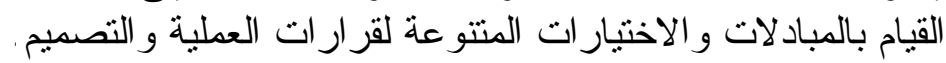

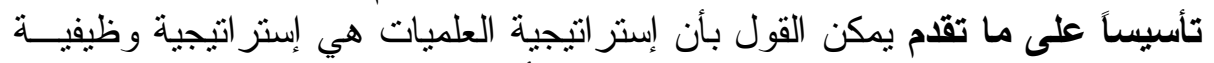

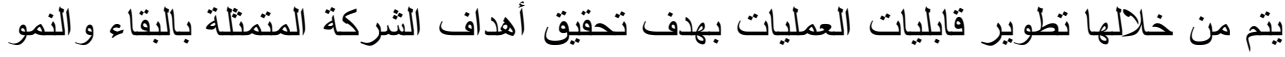

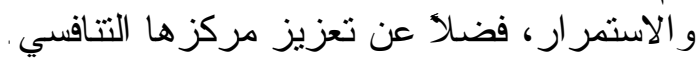

ثانياً - أبعاد إستر اتيجية العمليات

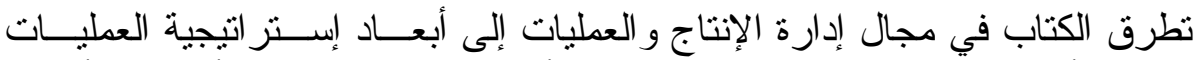

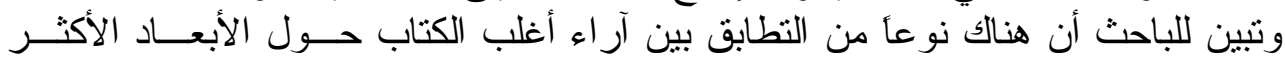

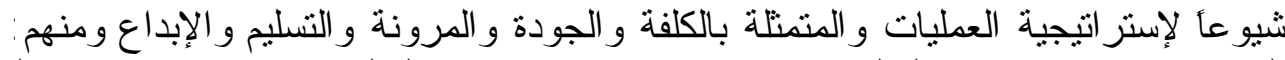

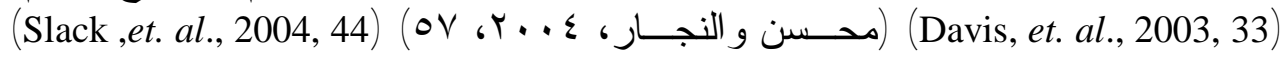

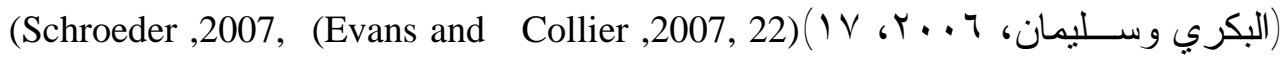

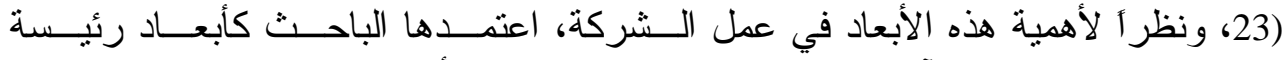

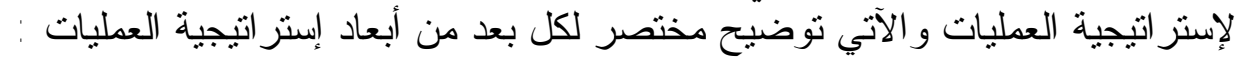

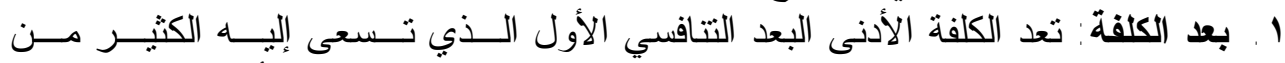

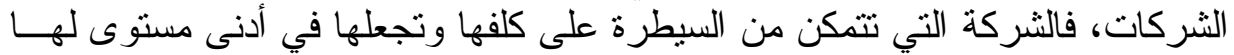

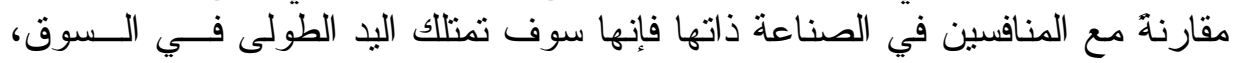

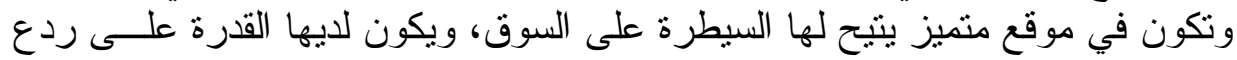




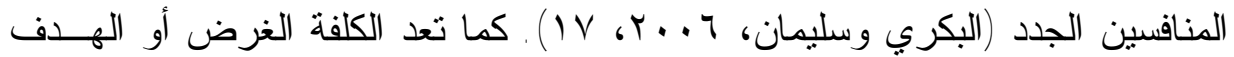

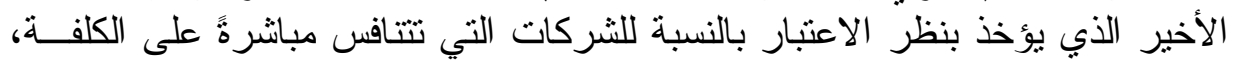

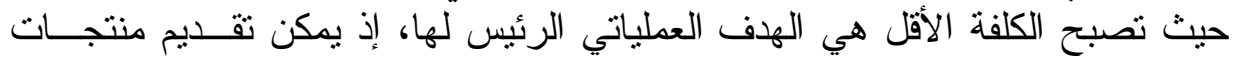

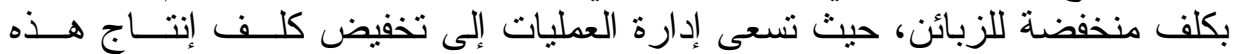

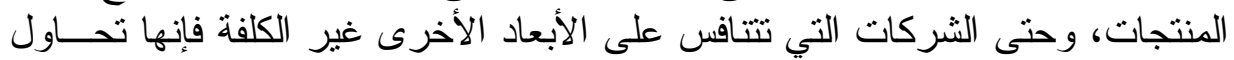

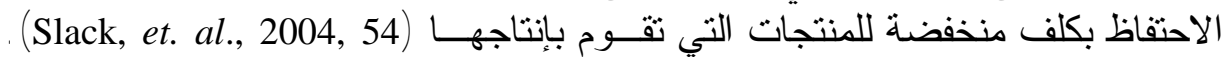

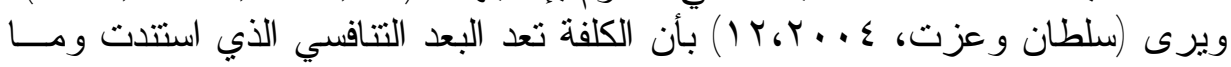

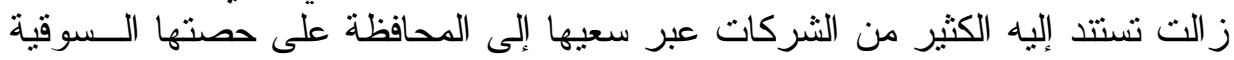

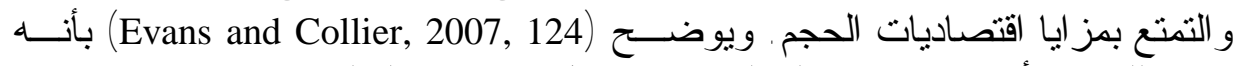

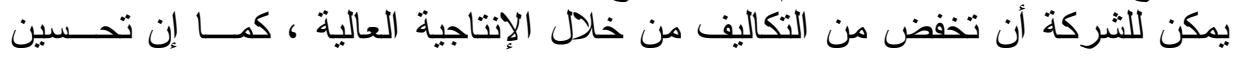

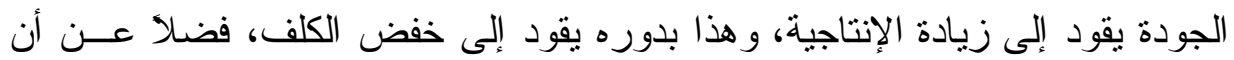

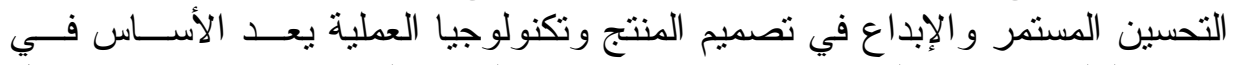

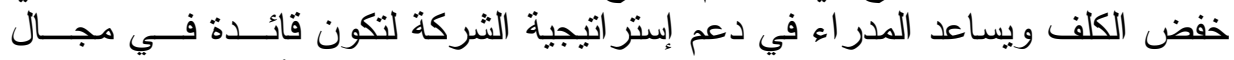

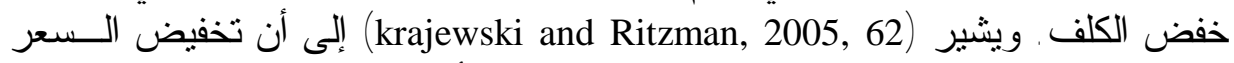

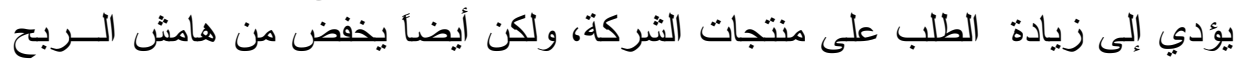

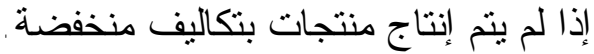

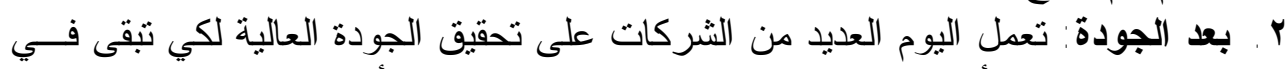

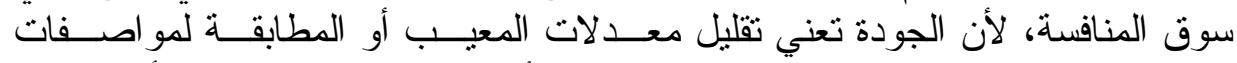

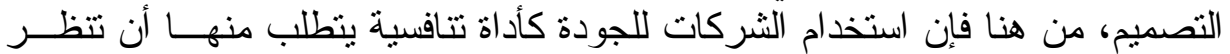

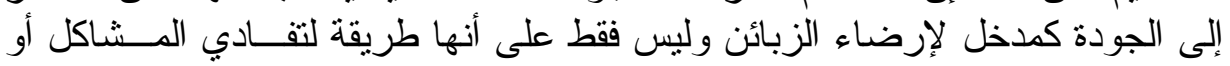

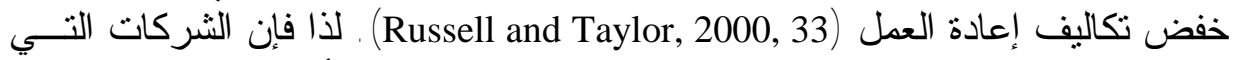

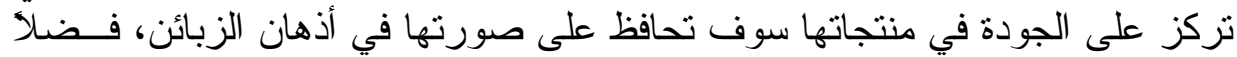

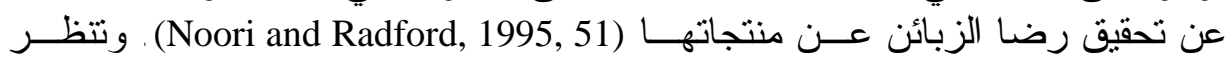

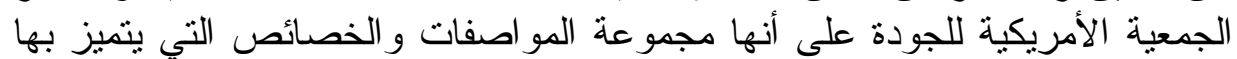

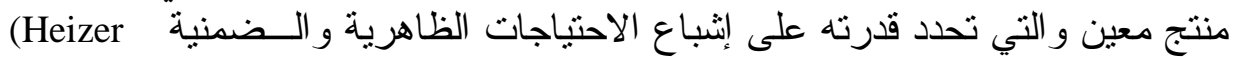

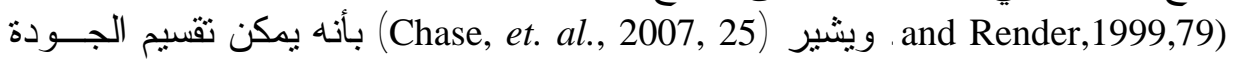

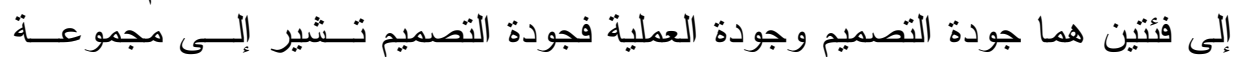

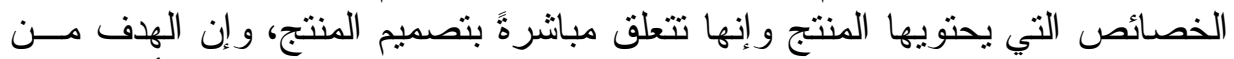

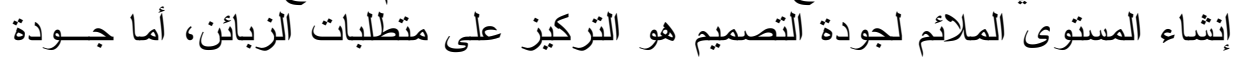

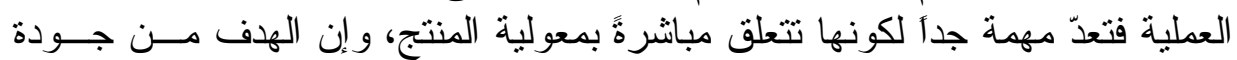

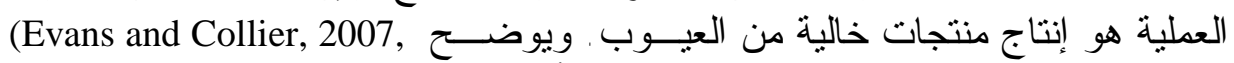

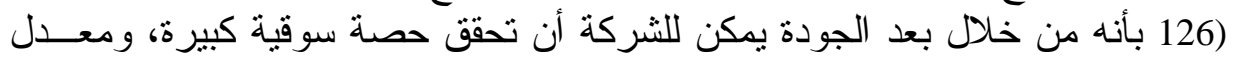

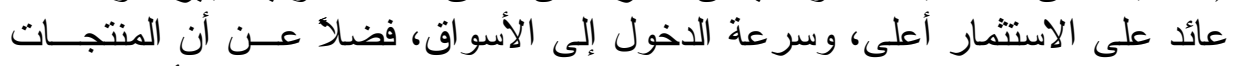

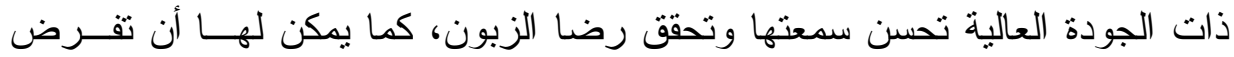

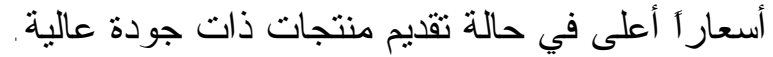

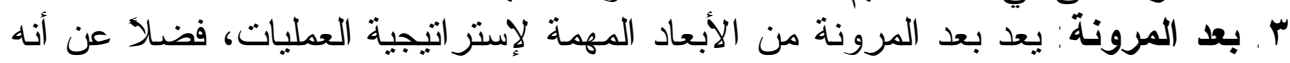

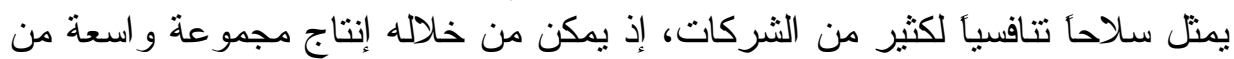

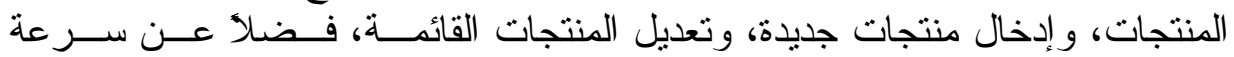




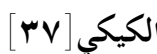

الاستجابة لاحتياجات الزبائن (Russell\& Taylor, 2000, 33). وعــرف (krajewski) and Retzman, 2005, 65) الاستجابة لاحتياجات زبائنها بسر عة وبكفاءة. ويبين (Chase, et. al., 2007, 26) بــأن

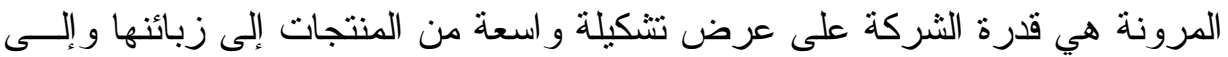

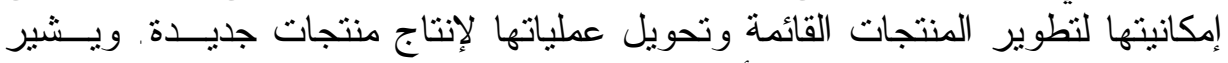
(Davis, et. al., 2003, 35) عمليات الثركة و هما:

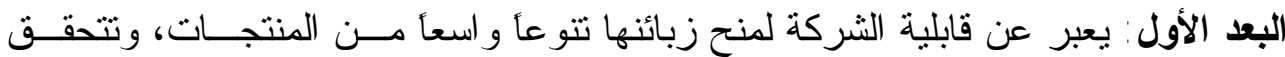

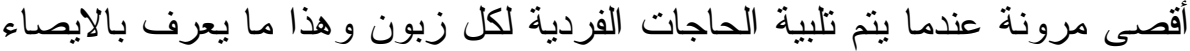

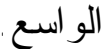

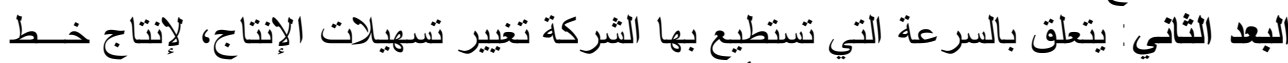

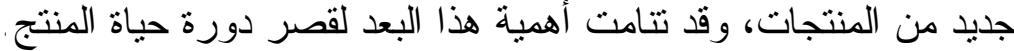
ويؤكد (Dillworth, 1996, 66) بأنه بمكن للشركة من خلال بعد المرونـــة تعـديل

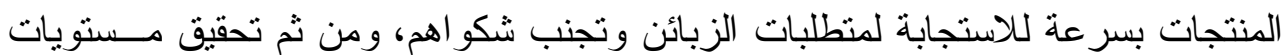

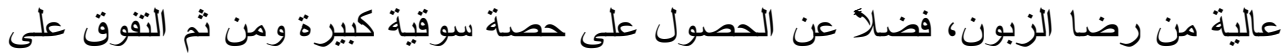

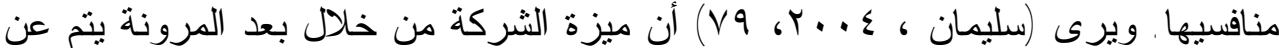

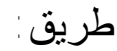
• القدرة على تخفيض الكلف الناتجة عن التحول من منتج إلى آخر ، ومن ثم سوف بــؤدي إلى تخفيض التكاليف الكلية.

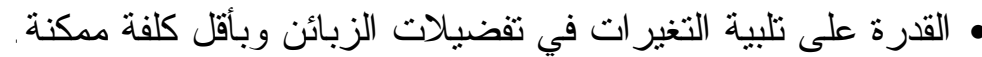

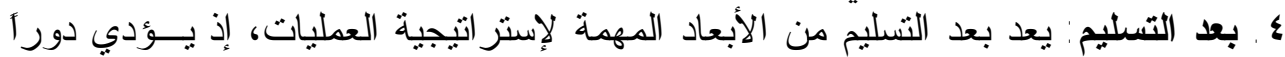

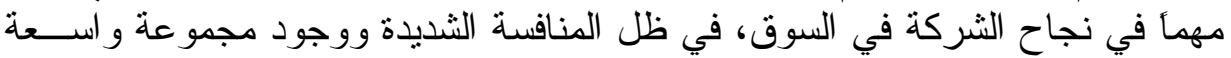

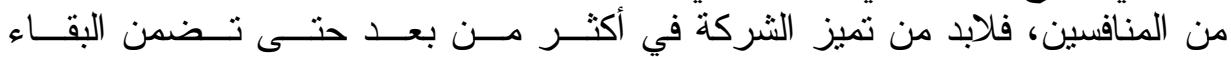

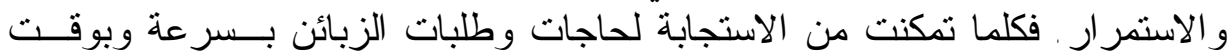

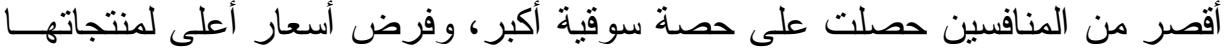

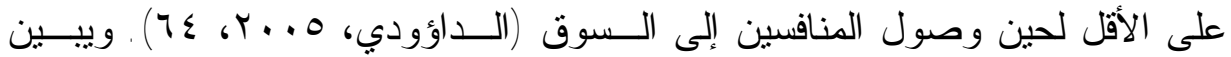
(Noori and Radford, 1995, 53)

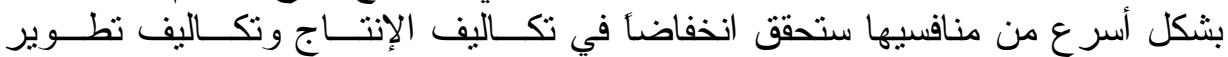

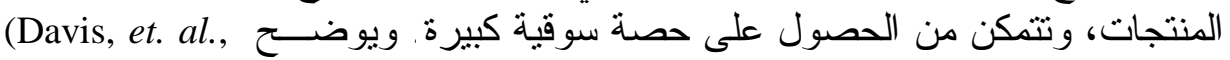

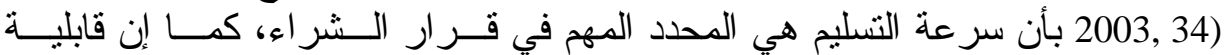

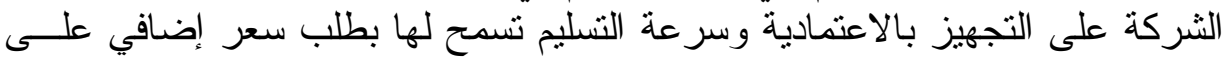

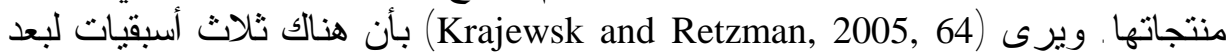

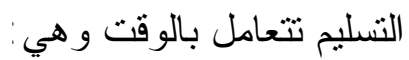

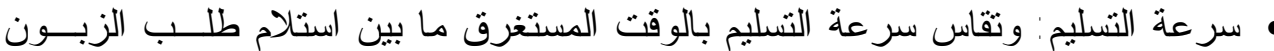
وتلبيته . • التسليم بالوقت المحدد : ويثير إلى تجهيز طلبات الزبائن في الموعد نفسها. • سرعة التطوير : وهي سرعة تقديم منتج جديد، وتقاس سرعة التطوير بالوقت بلت بين توليد

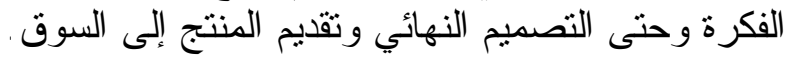


ويشير (Slack, et.al, 2004, 47-49) إلى النسليم من خلال سرعة التسليم و اعتمادية

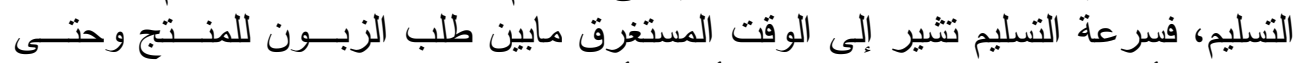

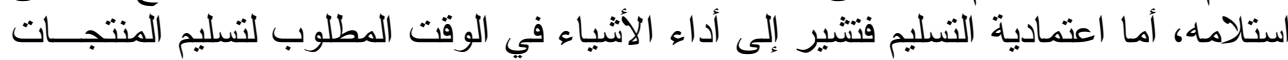

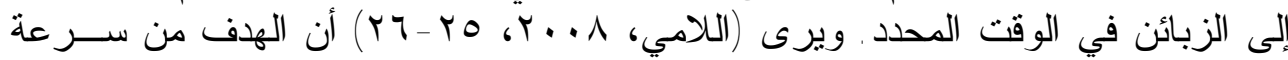

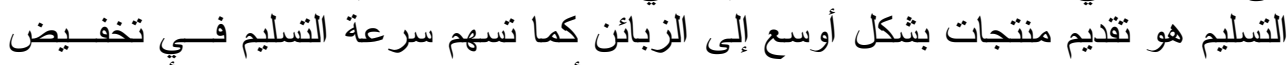

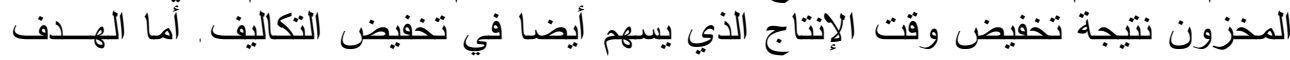

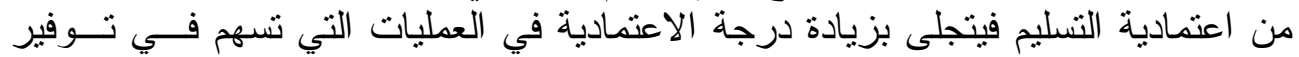

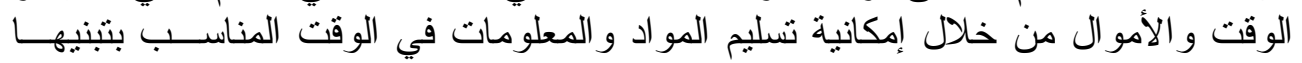

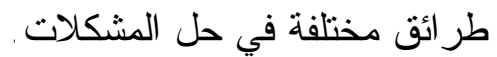
ه. بعد الإبداع: تتبنى الثركات التي تسعى إلى امتلالك الخاصية القيادية في تقانة المنتج،

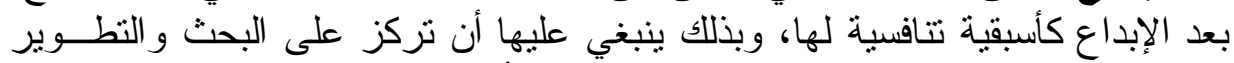

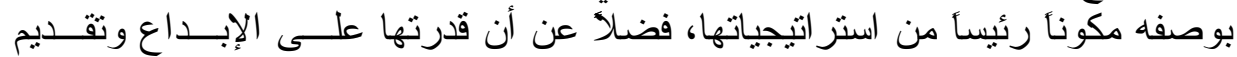

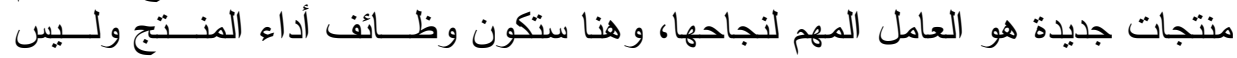

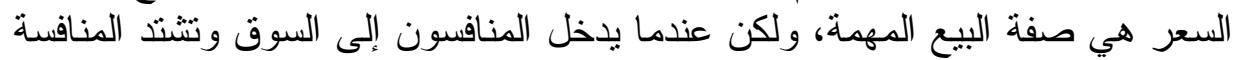

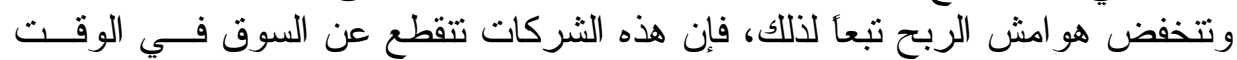

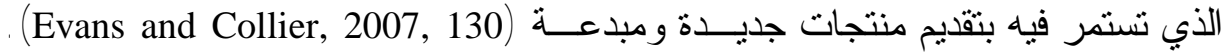

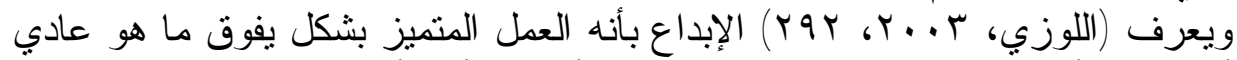

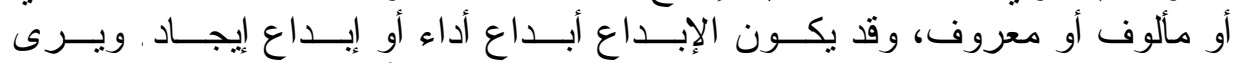
(Fakhredaei, 2006, 17)

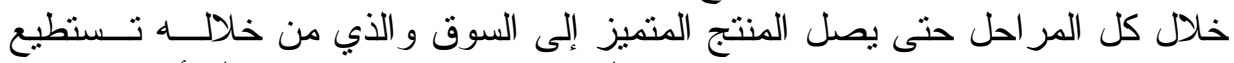

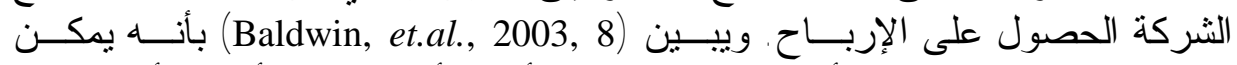

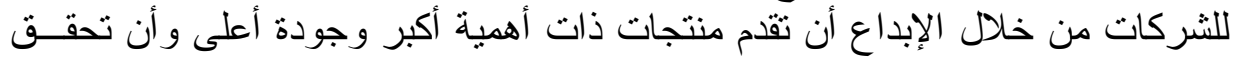

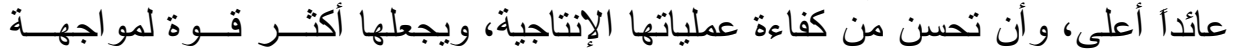

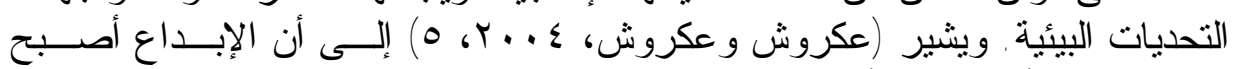

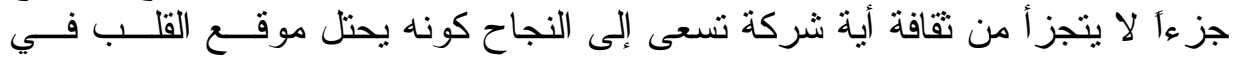

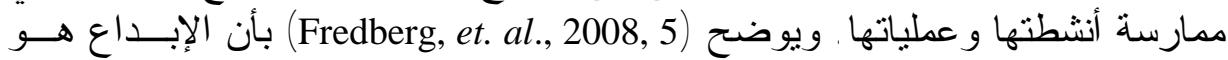

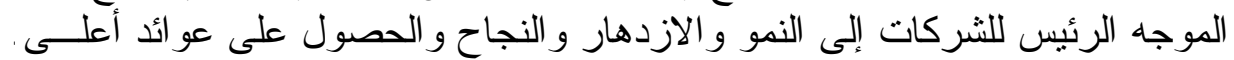

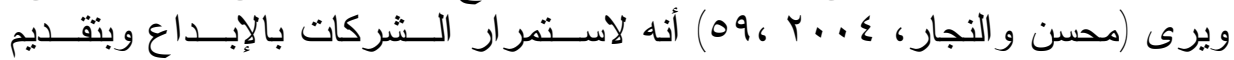

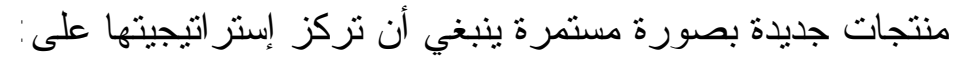

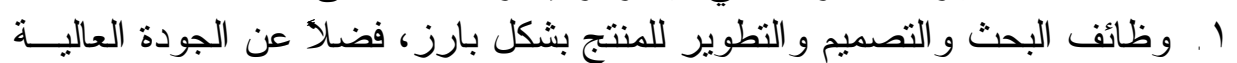
لإنتج r. امتلاك القدرة على تحوير أو تطوير معدات الإنتاج.

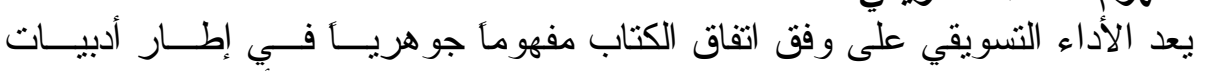

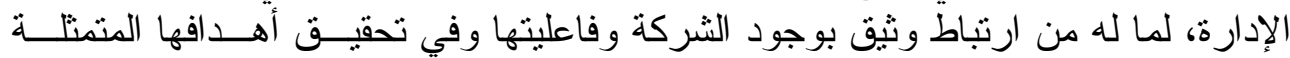

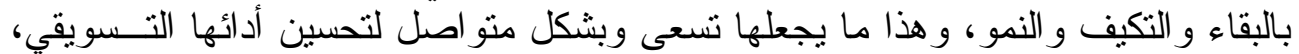

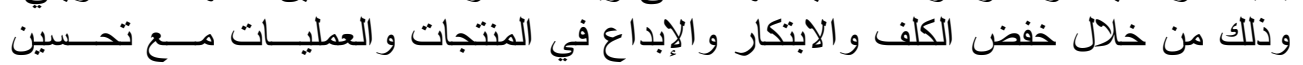




\section{الكيكي[a}

الجودة و الإنتاجية من أجل زيادة قدر اتها التنافسية، ولقد وردت تعـــاريف عديــدة لــلأداء

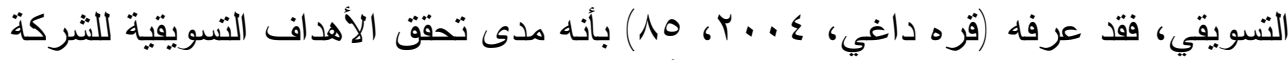

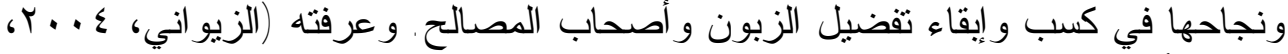

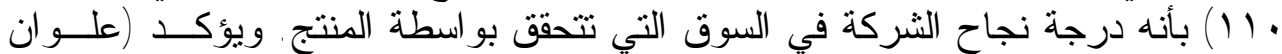

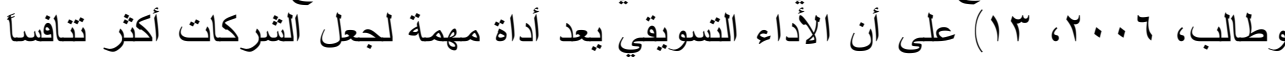

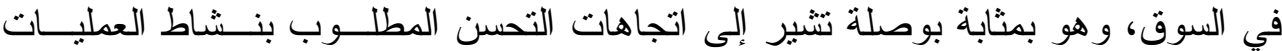

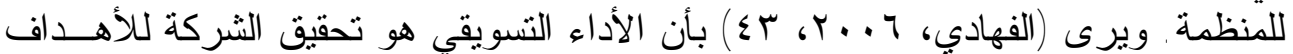

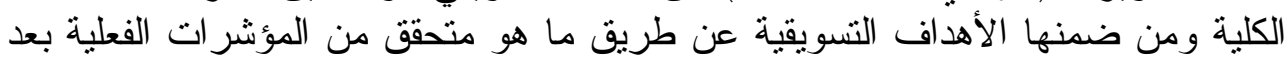

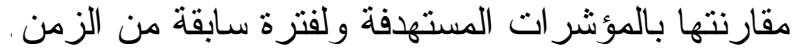

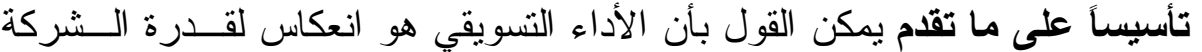

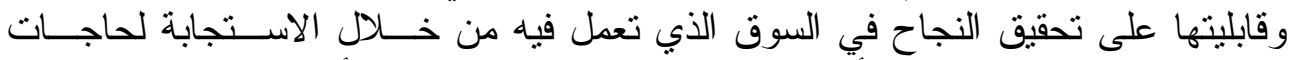

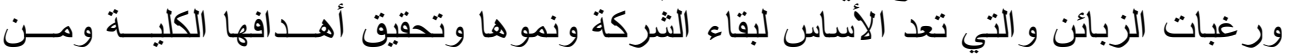
ضمنها الأهداف التسويقية.

\section{رابعاً - مؤشرات قياس الأداء التسويقي}

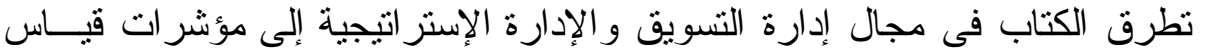

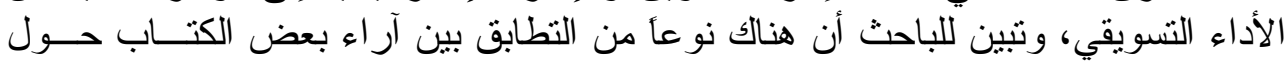

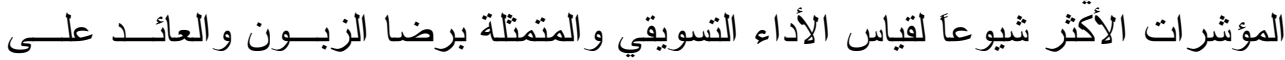

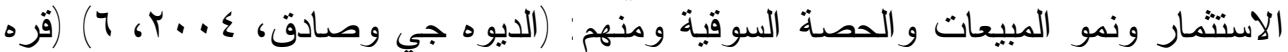

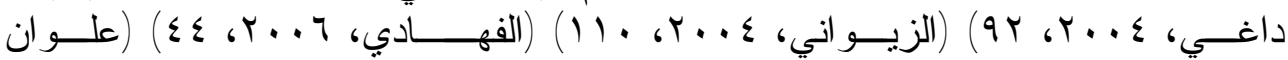

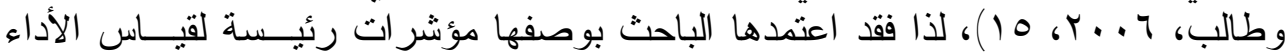
التسويقي و الآتي عرض موجز لكز لكل منها:

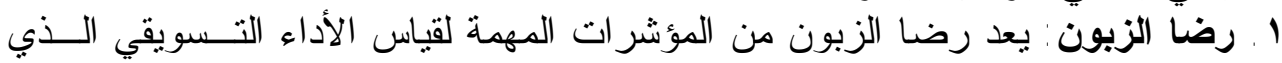

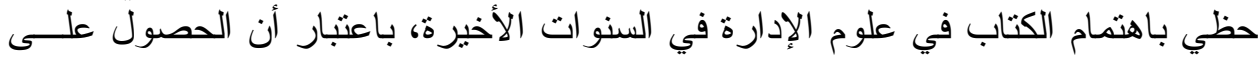

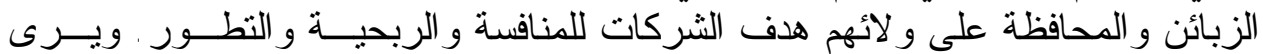

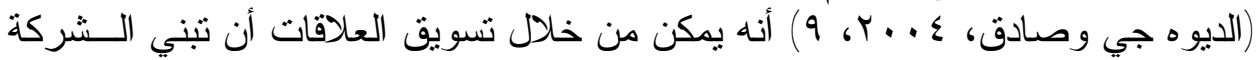

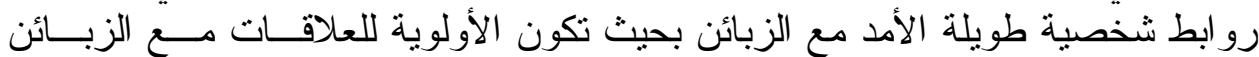

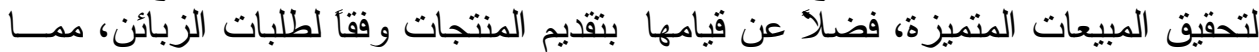

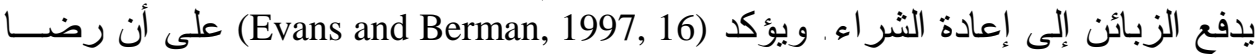

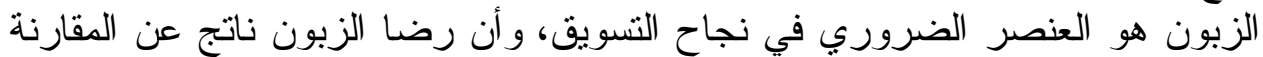

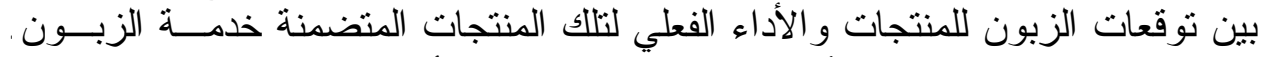

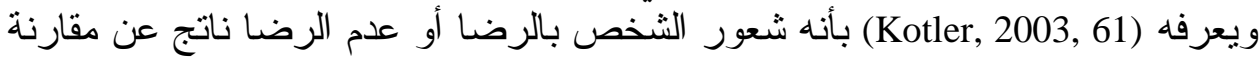

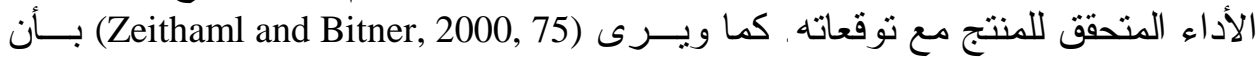

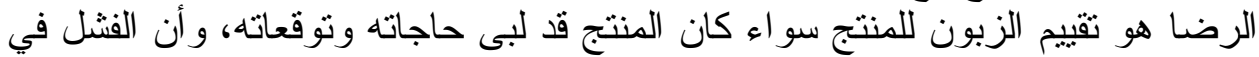

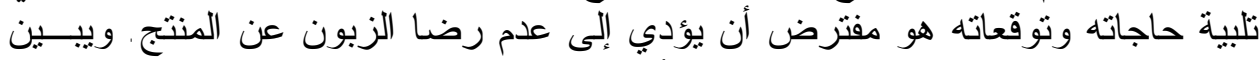

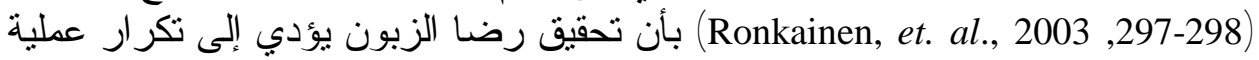

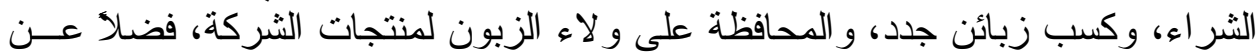

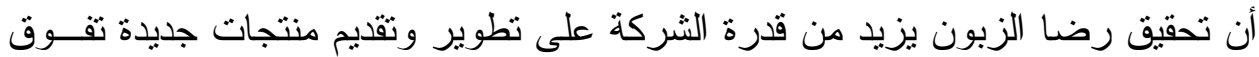

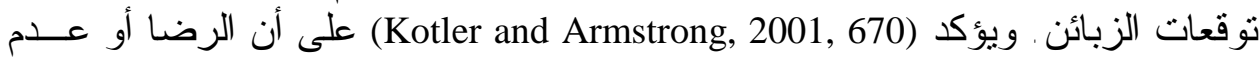




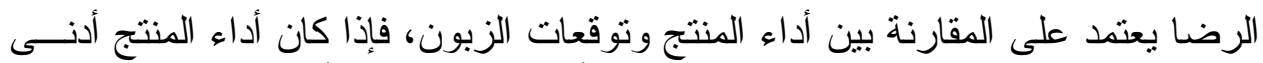

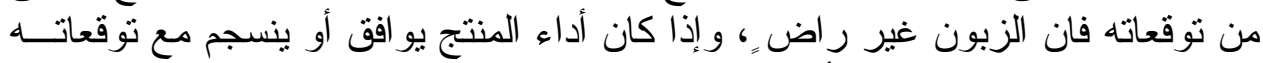

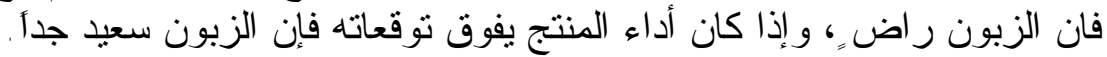

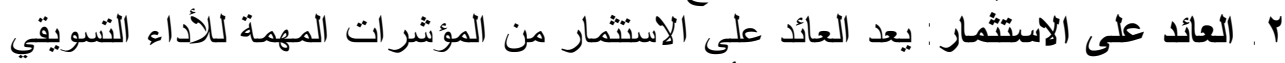

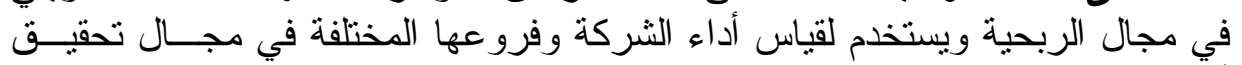

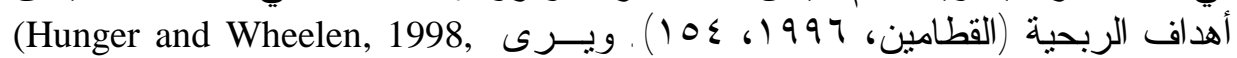

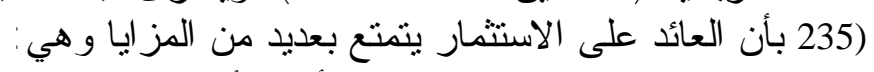

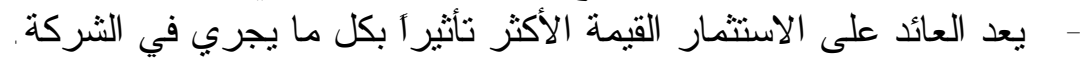

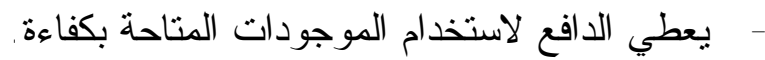

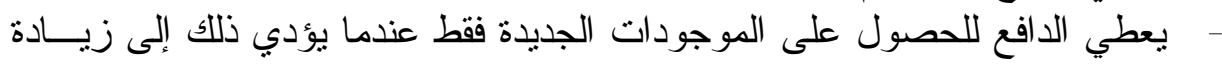

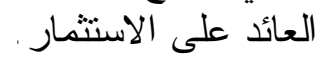

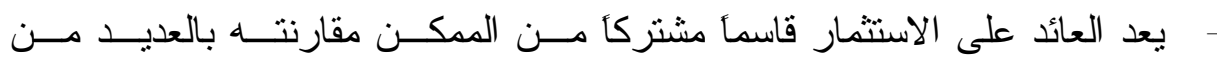

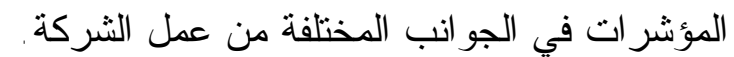

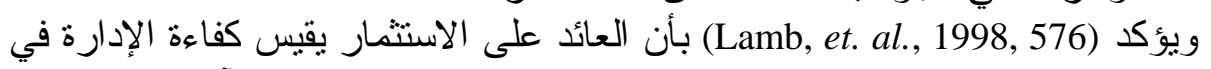

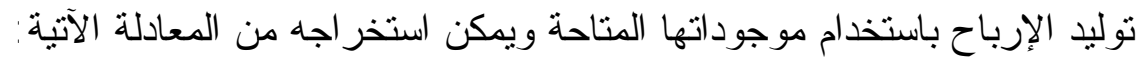

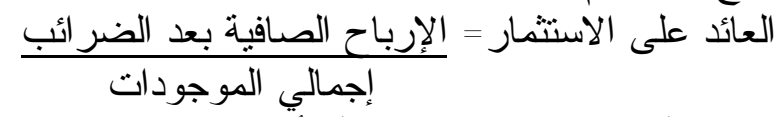

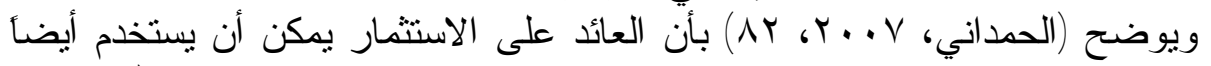

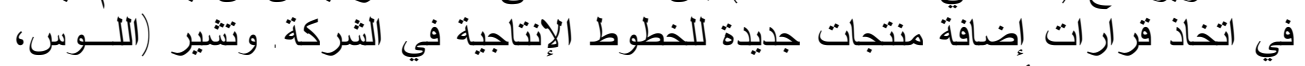

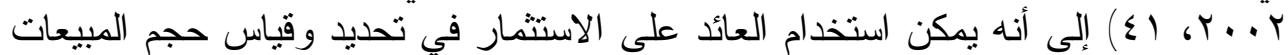

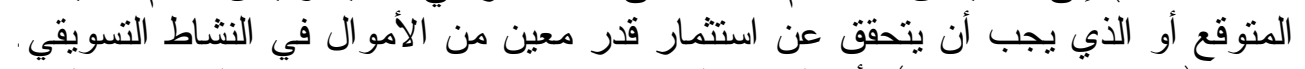

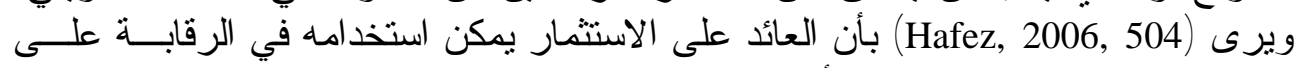

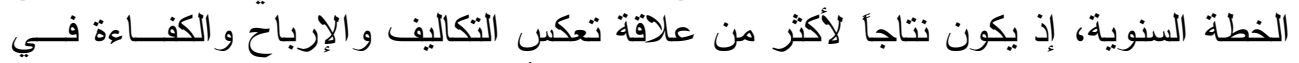

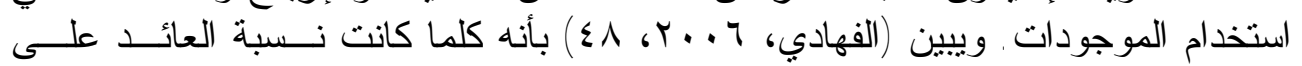

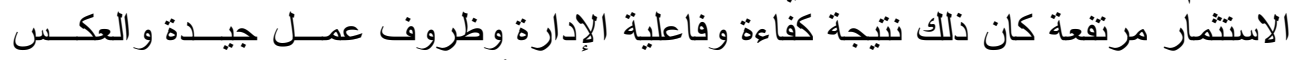

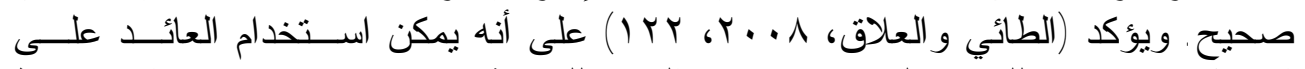

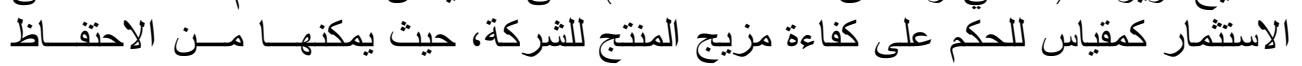

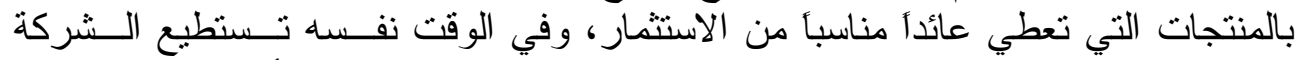

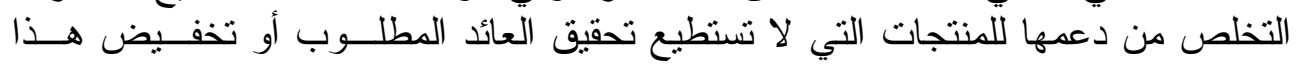

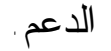

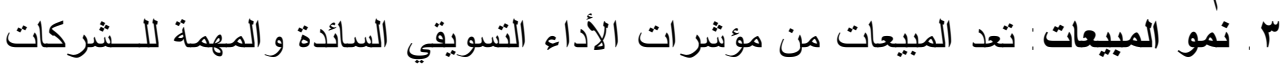

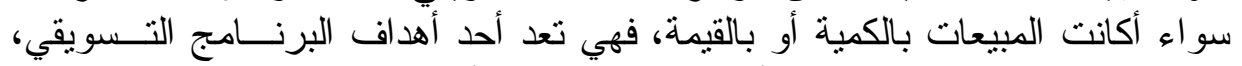

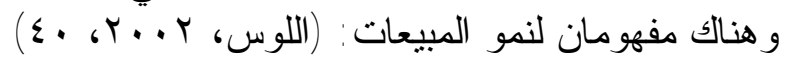

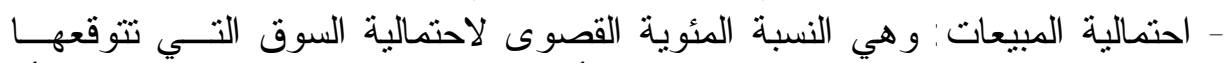

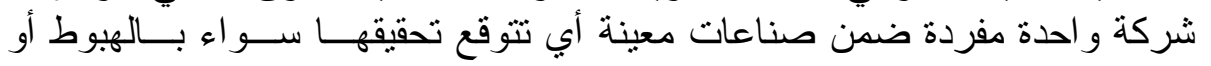

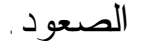

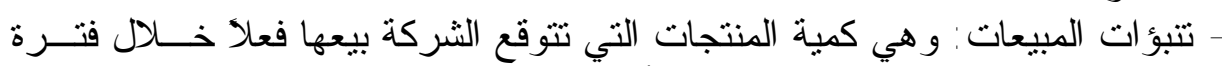

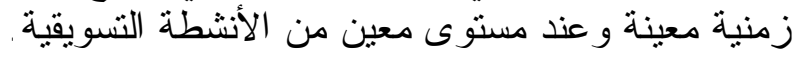




\section{الكيكي[1 إ (2)}

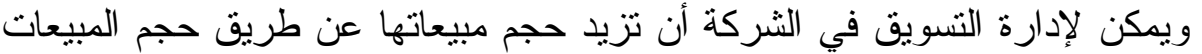

المرتقب وحجم المبيعات التقديري، اذ يشير الأول إلى الرقم الذي تأمل الثركة تحقيق تحقيقه، أما

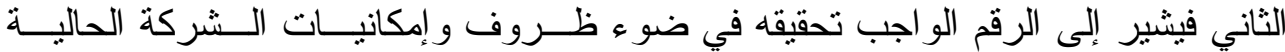

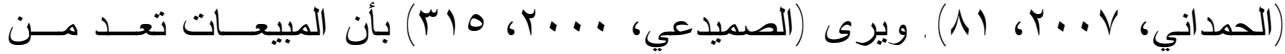

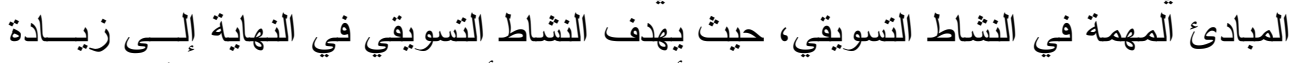
حجم المبيعات، و هذا الحجم هو المعيار الأول لنجاح الأداء التسويقي. ويؤكد (الديوه جي،

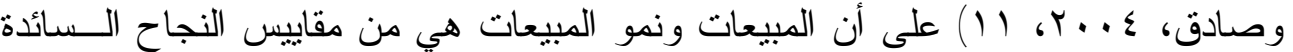

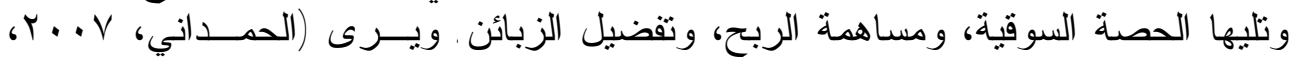
1 10) بأنه يمكن استخر اج معدل نمو المبيعات من خلال الرعادلة الآتية:

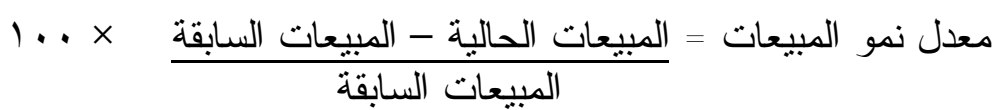

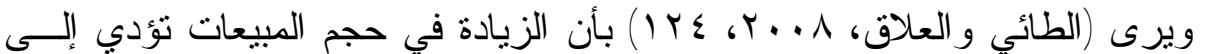

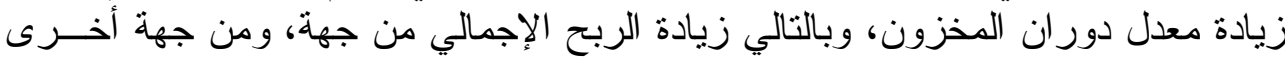
فإن الزيادة في حجم المبيعات يمكن الثركة من الاستفادة من مز ايا منحنى الخبرة انطلاقاً

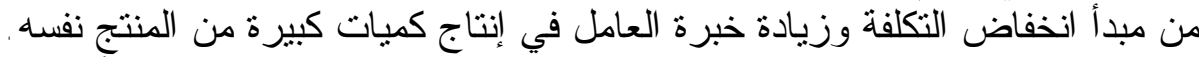

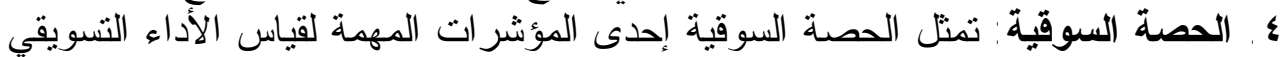

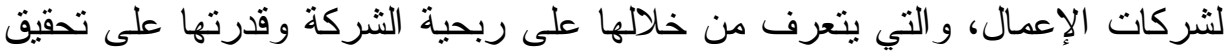

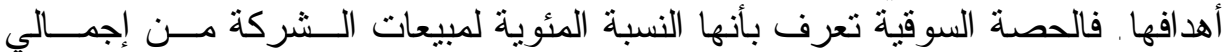

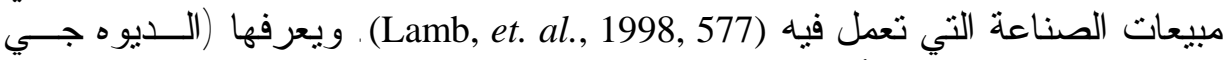

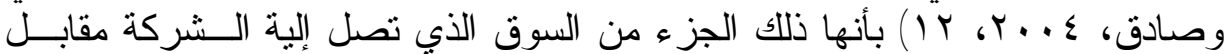

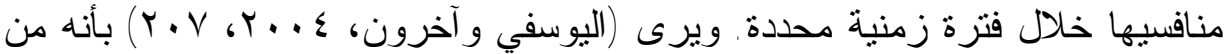

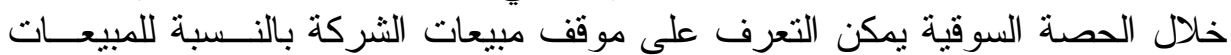

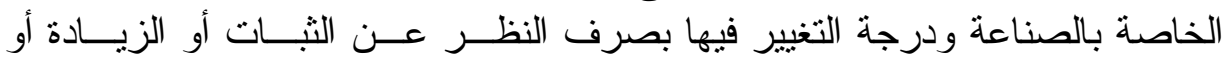

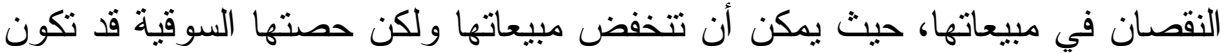

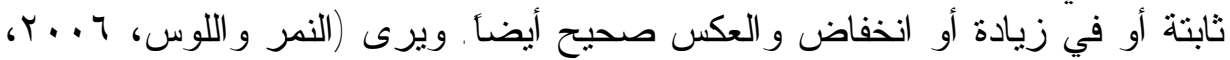

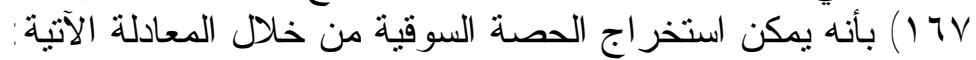

$$
\text { الحصة السوقية للشركة = مبيعات الثركة × مبيعات الصناعة }
$$

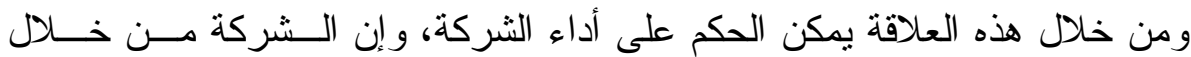

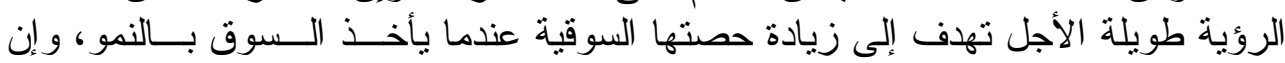
الرغبة في زيادة الحصة السوقية قد يؤدي إلى انخفاض الربحية في الأمد القصير ، ثم تبدأ

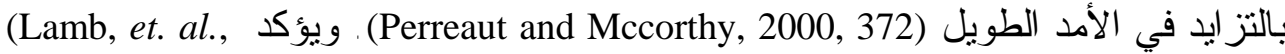
(1998, 577 أن الزيادة في الحصة السوقية يستدل منها إلى أن المزيج التسويقي للـشـركة

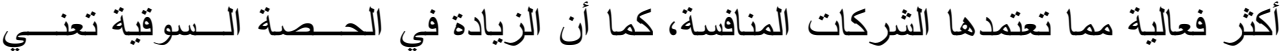

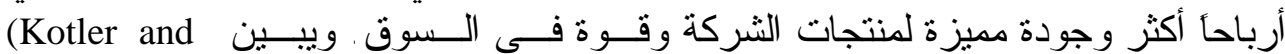

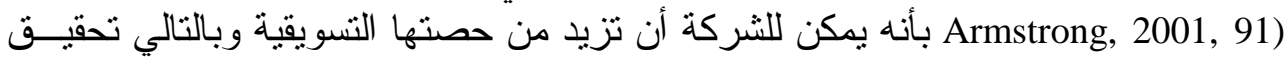


الإرباح عندما تكون كلفة الوحدة الو احدة من المنتج منخفضة و عندما تقدم منتجات بجـودة

الجاتب الميداني بهذف بيان العلاقة و الأثر بين أبعاد إستر اتيجية العمليات و الأداء التسويقي يـستلزم

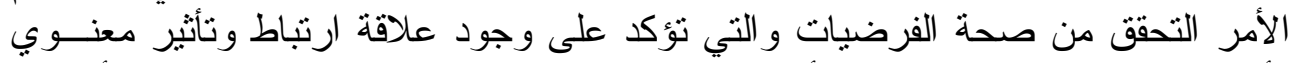

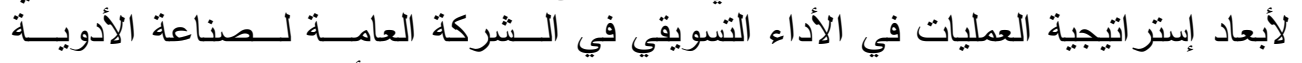

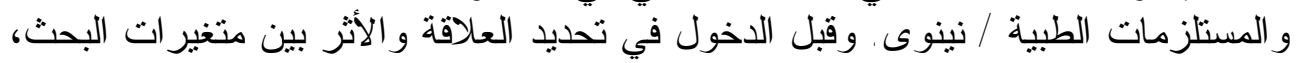

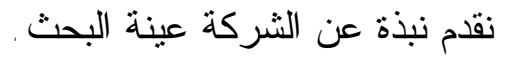

$$
\text { أولاً - وصف عينة البحث }
$$

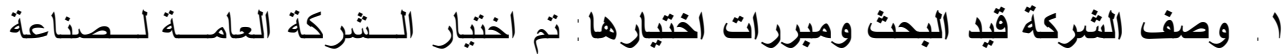

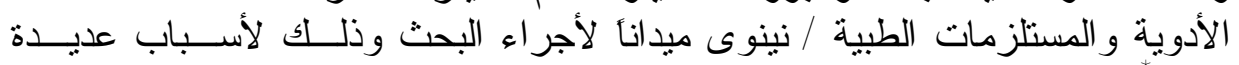
أهمها : الادوبة: • كونها من الثركات الصناعية الكبيرة نسبياً في محافظة نينوى و الوحيدة في مجــال

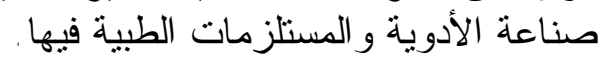

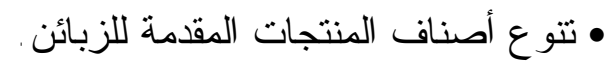

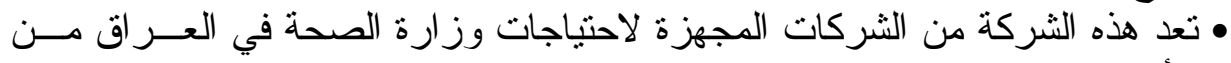

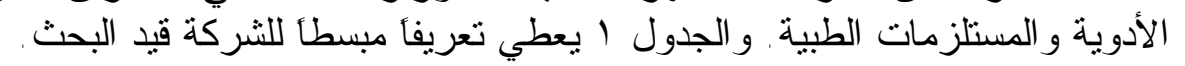

\begin{tabular}{|c|c|c|}
\hline منتجات الشركة & نبذة مختصرة عن الثركة & الشركة \\
\hline 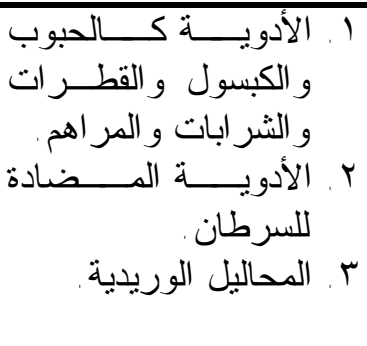 & 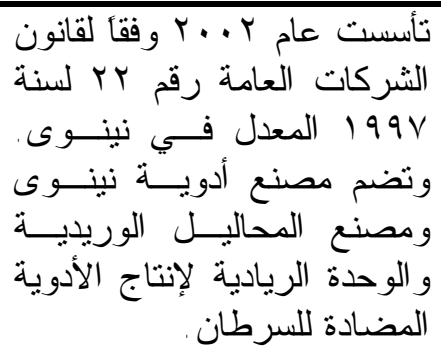 & 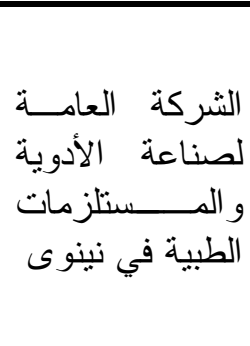 \\
\hline
\end{tabular}

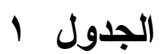

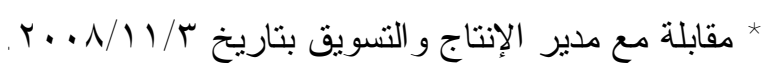

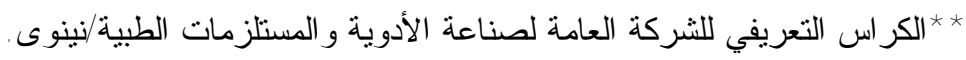




\section{الكيكي[r}

r. وصف الأفراد المبحوثين: تم اختيار الأفر اد العاملين في الــشركة المبحوثــة الـــين

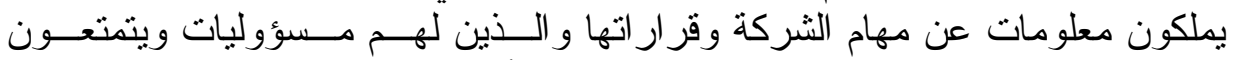

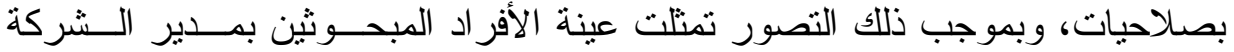

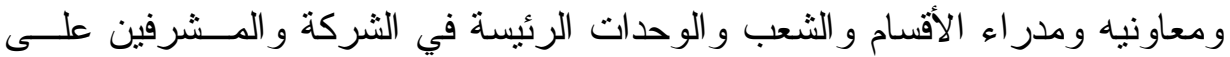

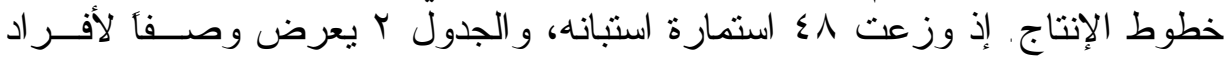
عينة البحث بحسب المركز الوظيفي و التحصيل الدر اسي ومدة الخدمة للمبحوثين فـي ولئي الثركة قيد البحث .

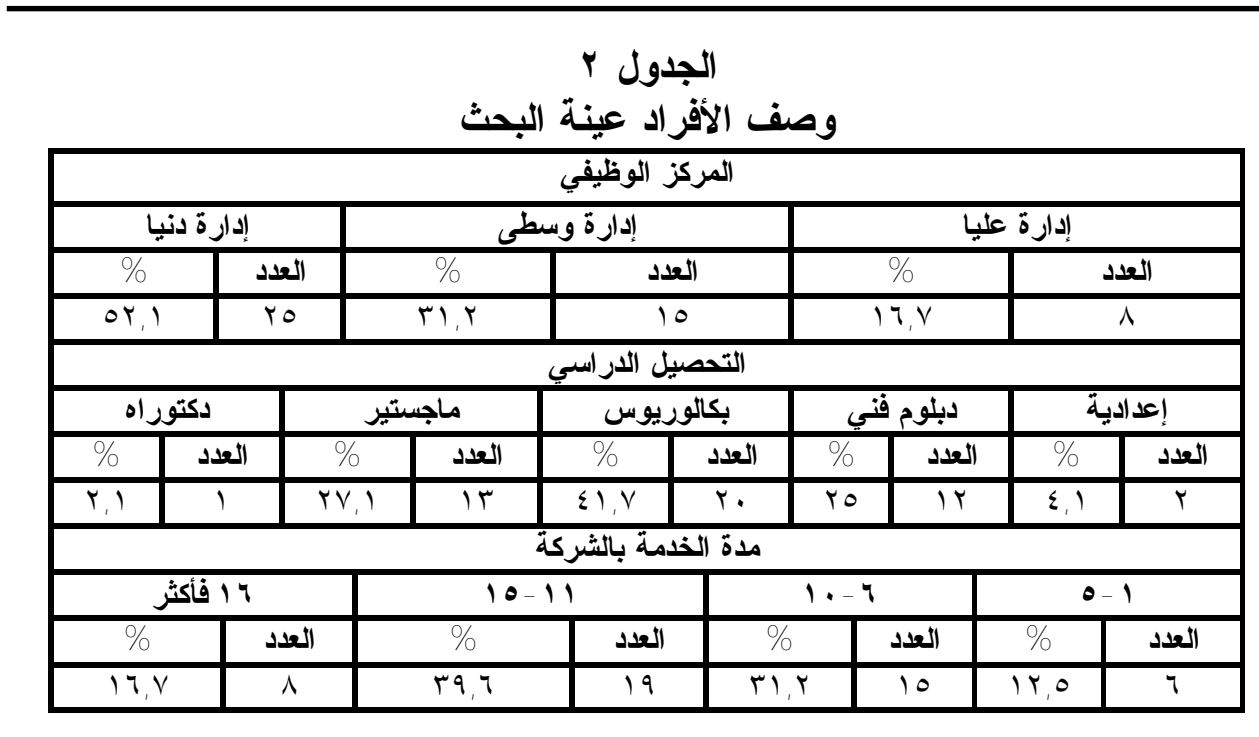

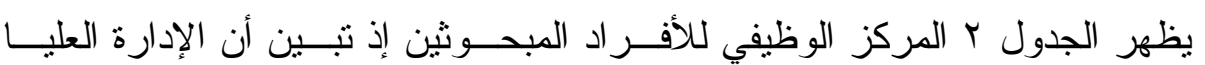

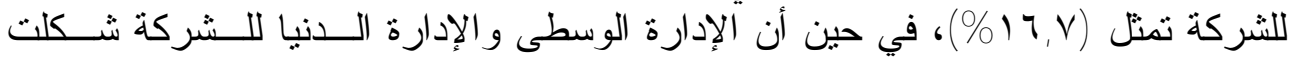

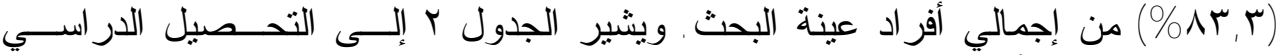

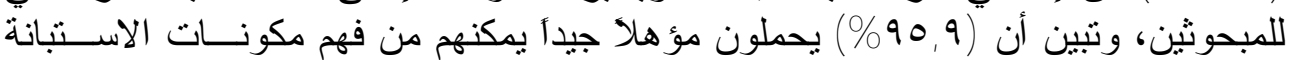

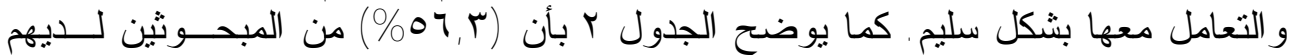

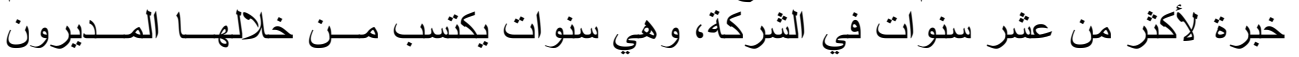

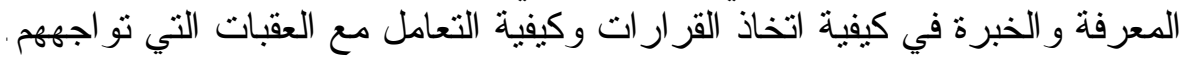

ثانياً - اختبار أنموذج البحث وفرضياته بهدف التعرف على طبيعة العلاقة و الأثر بين أبعاد إبــتر اتيجية العمليـات و الأداء

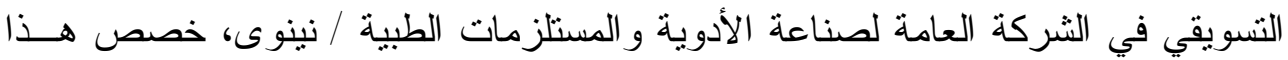

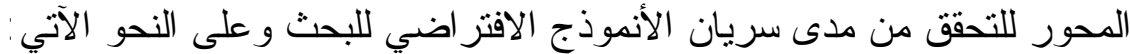

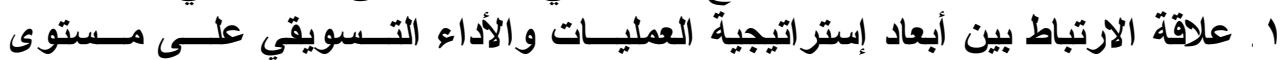

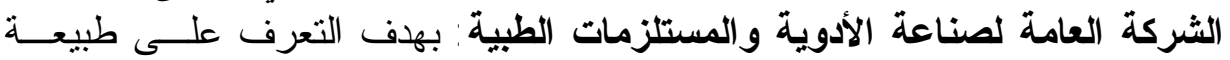
و اتجاه علاقات الارتباط بين أبعاد إستر اتيجية العمليات و الأداء التسويقي على التئي مستوى

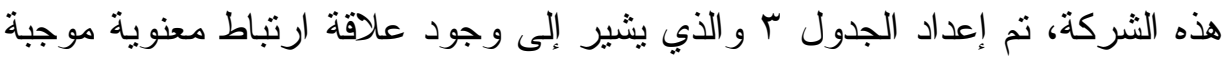

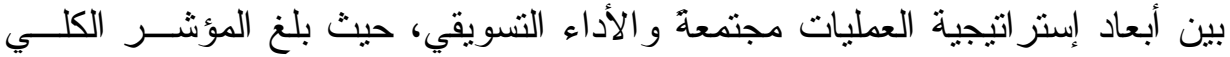




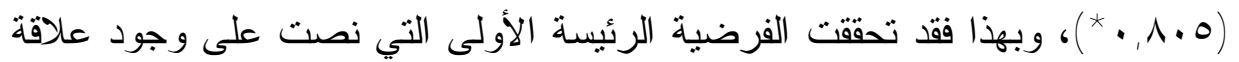

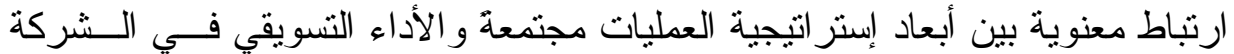

\begin{tabular}{|c|c|c|c|c|c|c|}
\hline \multicolumn{7}{|c|}{ 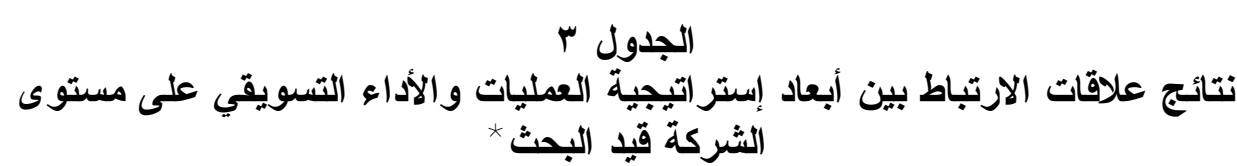 } \\
\hline \multirow{2}{*}{ الكؤشر } & \multicolumn{4}{|c|}{ الأداء التسويقي } & \multirow{2}{*}{\multicolumn{2}{|c|}{ المتغير ات المستفله اتهير المعتمدة }} \\
\hline & السوقية & المبيعات & الاستثثمار على & رالزبون & & \\
\hline$\cdot, V \leqslant V$ & $\cdot, T \leqslant 1$ & $\cdot, 7 \wedge \mathrm{V}$ & $\cdot, 70 \mathrm{~V}$ & $\cdot, 7.9$ & الكلفة & \multirow{5}{*}{ 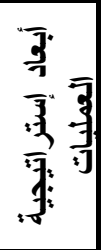 } \\
\hline$\cdot, \pi 7 \varepsilon$ & $\cdot, 7 \cdot r$ &., $0 \vee 0$ & $\cdot, 7 \leqslant$. & ${ }^{*},, 771$ & الجودة & \\
\hline$\cdot, v 1$. &., OYY &., $0 \mathrm{VI}$ & .071 & ${ }^{*}, ., O V Y$ & المرونة & \\
\hline., 011 &., $0 \mathrm{VA}$ & .047 &., $7 \leqslant \pi$ & ${ }^{*} .074$ & التسليم & \\
\hline., $7 \pi 1$ &., $01 \mathrm{~V}$ & $\cdot, 0 . Y$ & $\cdot, V) \leq$ & ${ }^{*}, 7,7,0$ & الإبداع & \\
\hline.$\wedge .0$ & & & & & \multicolumn{2}{|c|}{ المؤشر الكلي } \\
\hline
\end{tabular}

وبهدف إعطاء مؤشرات تفصيلية بين أبعاد إستر اتيجية العمليات و الأداء التـسويقي

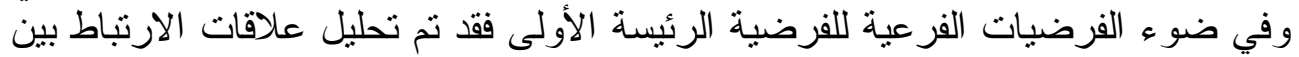

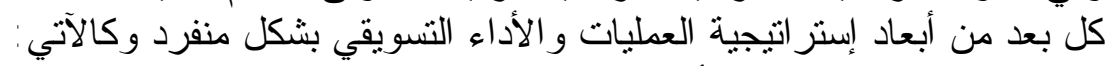

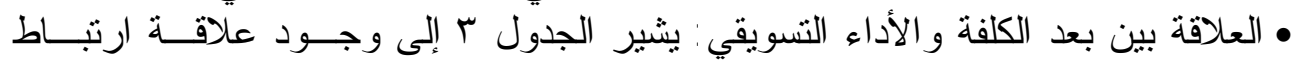

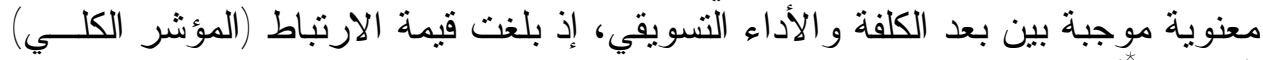

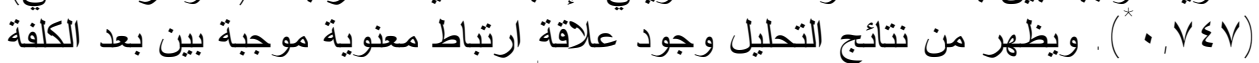

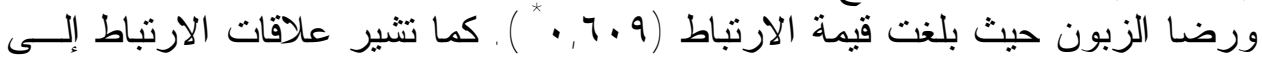

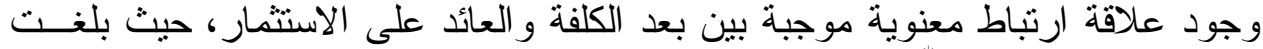

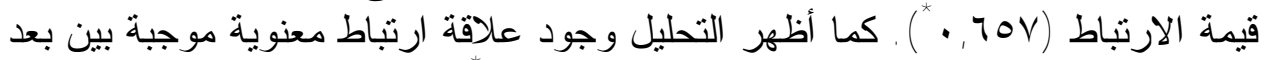

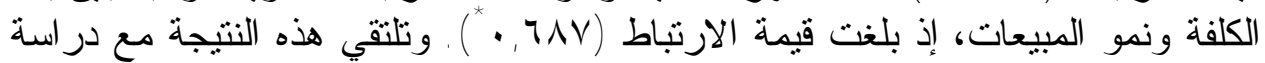

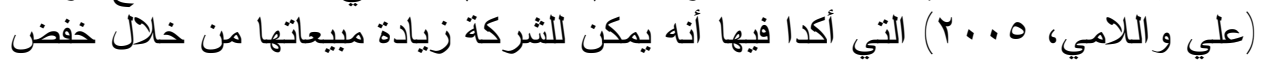

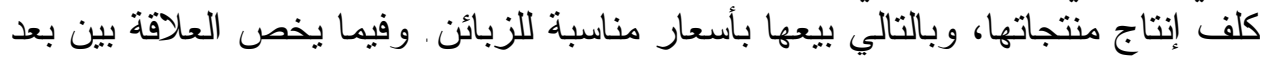

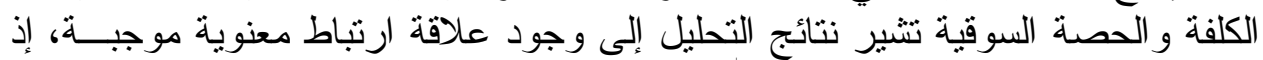

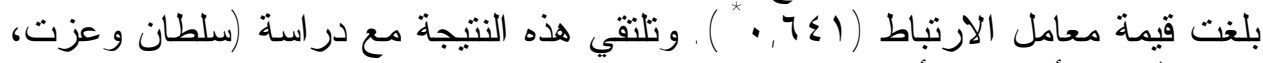

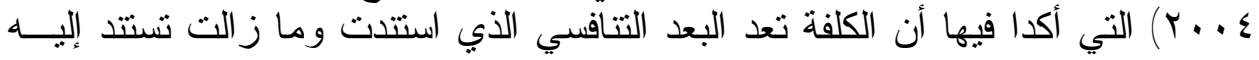

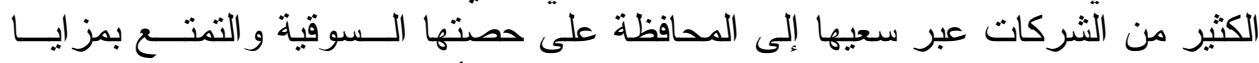

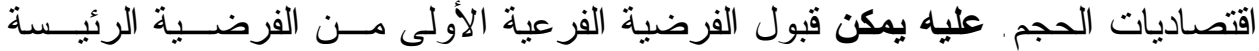

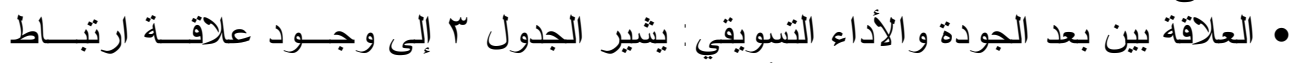

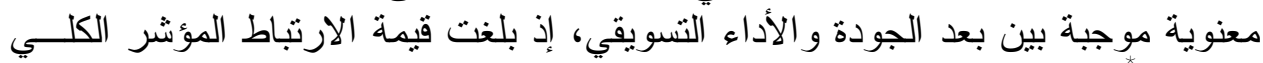

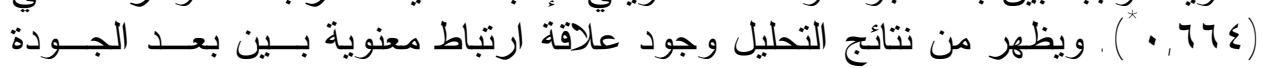




\section{الكيكي[0]}

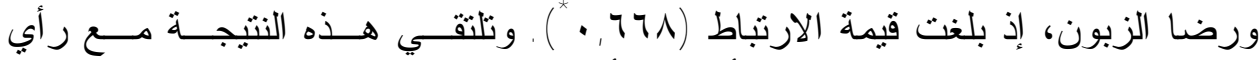
(Russell and Taylor, 2000)

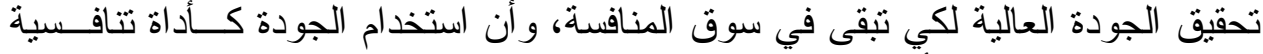

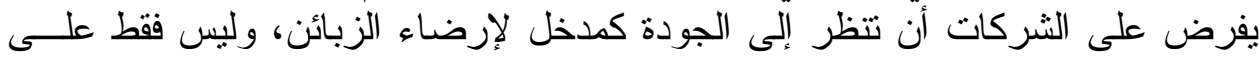

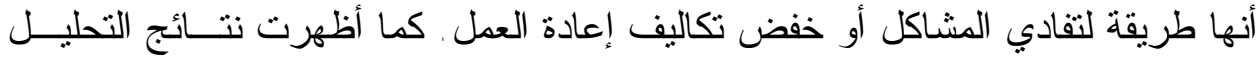

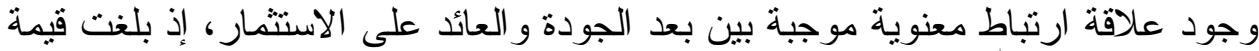

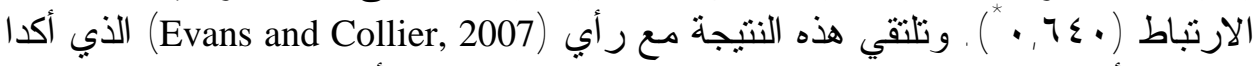

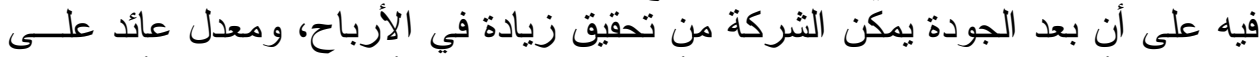

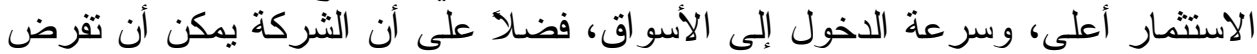

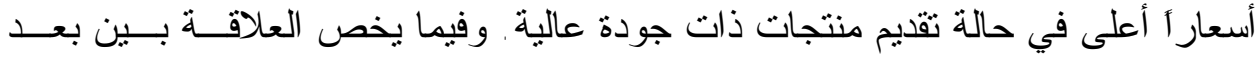

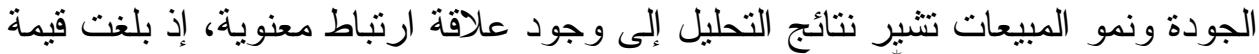

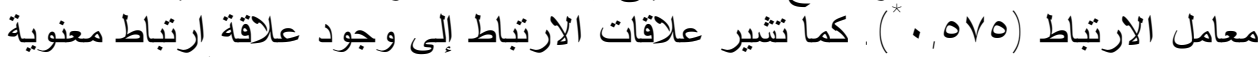

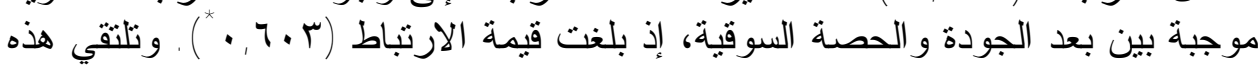

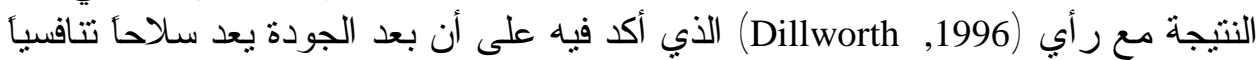

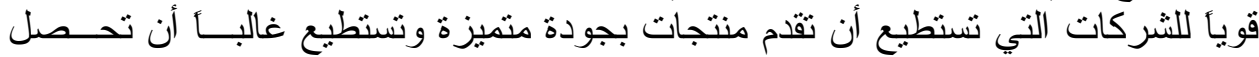

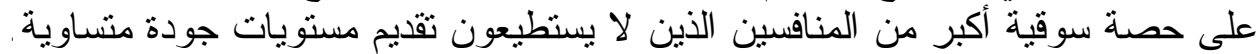

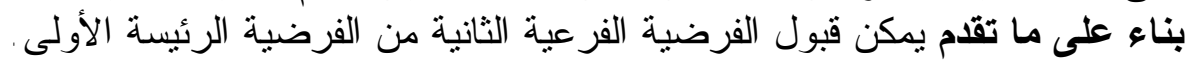

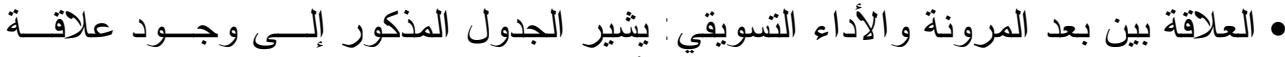

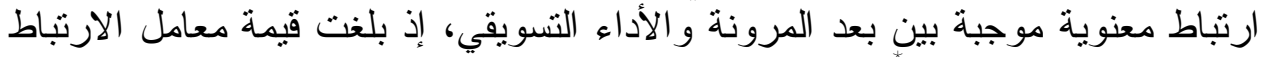

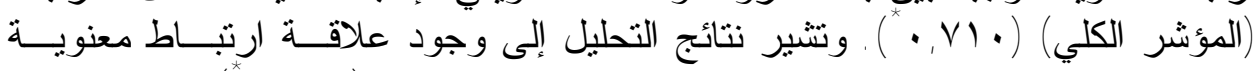

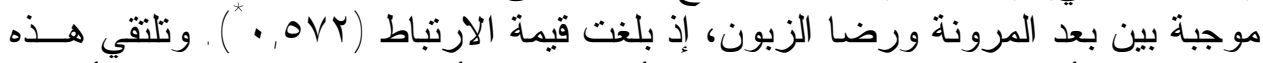

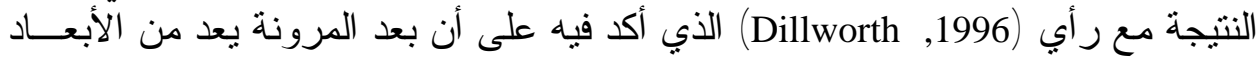

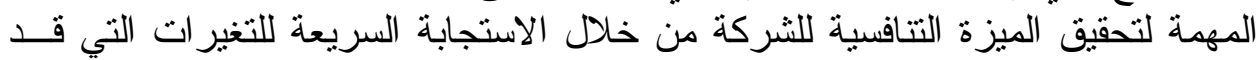

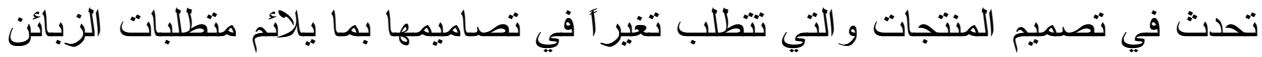

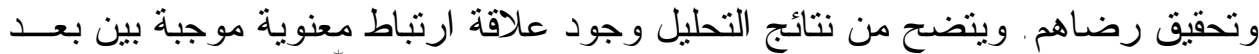

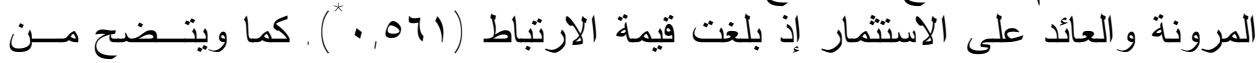

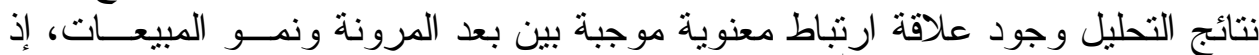

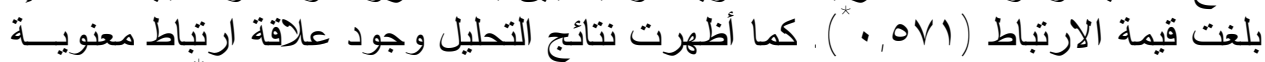

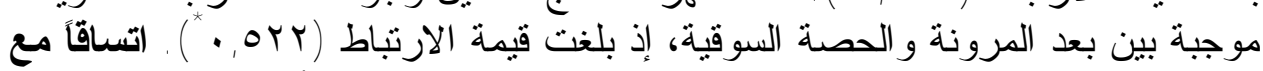

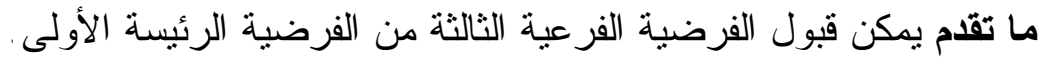

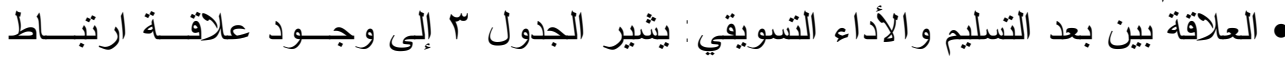

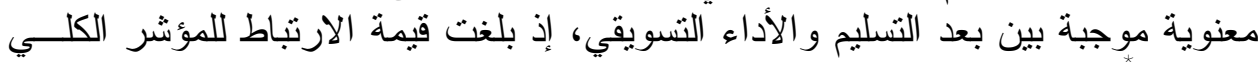

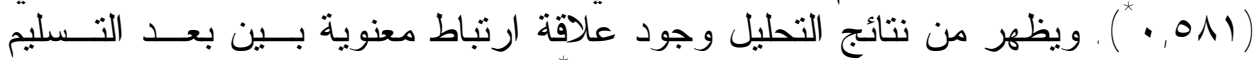

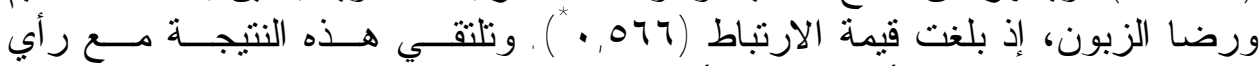

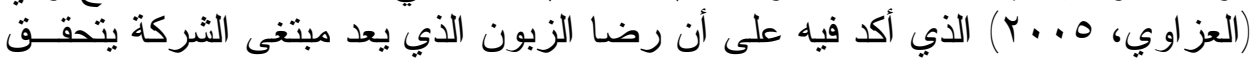

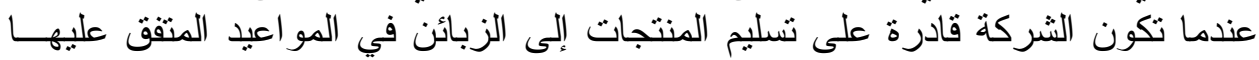

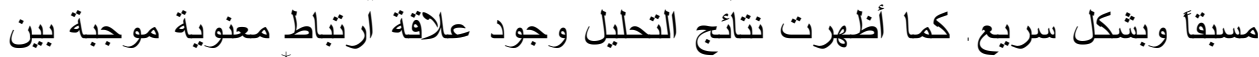

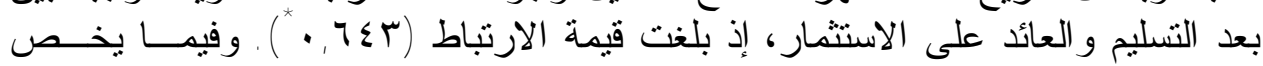

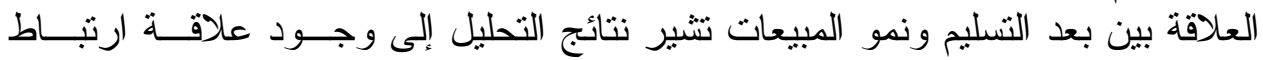




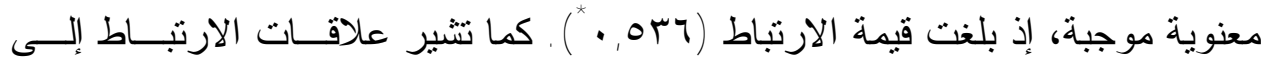

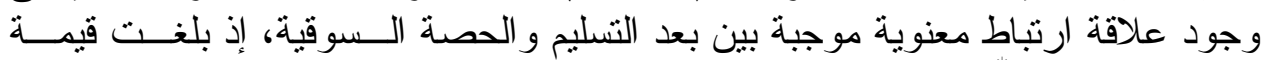

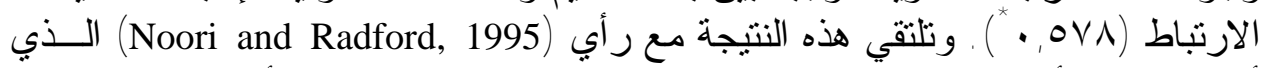

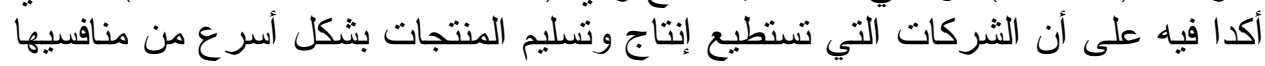

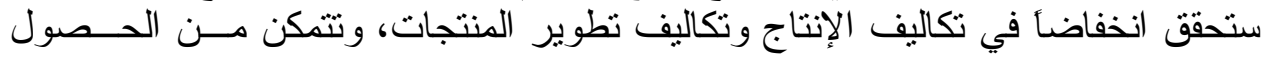

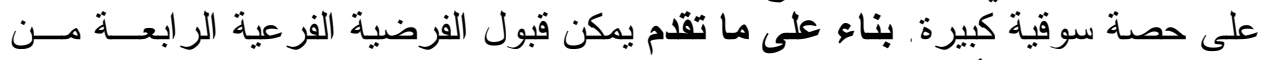

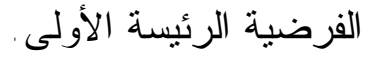

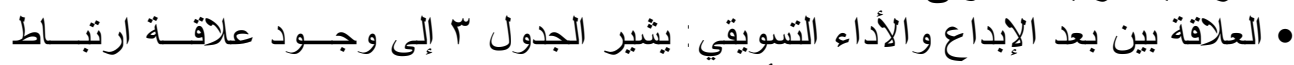

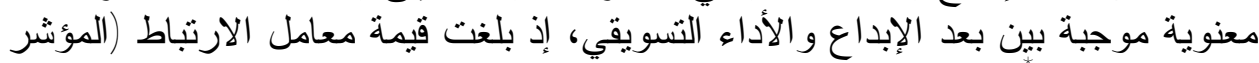

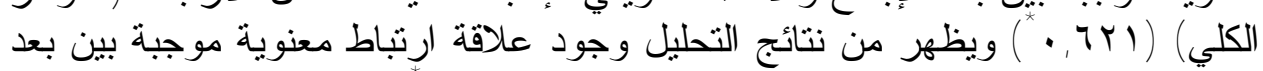

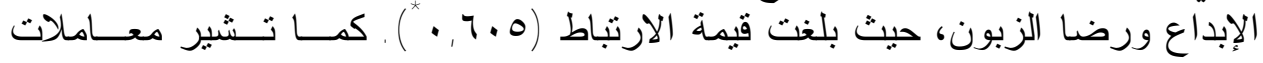

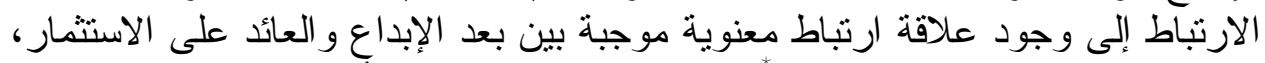

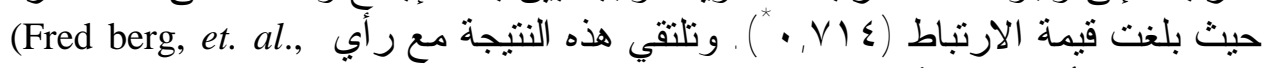

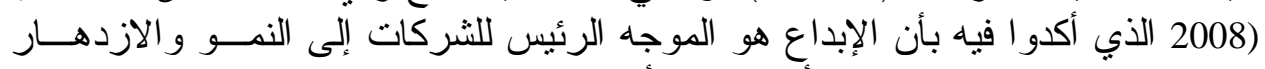

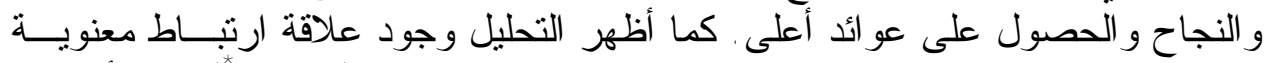

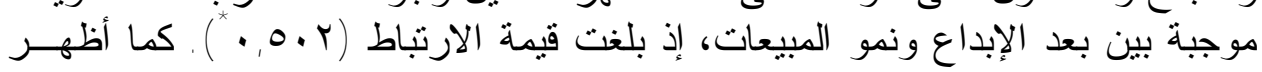

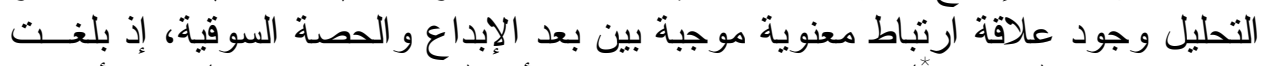

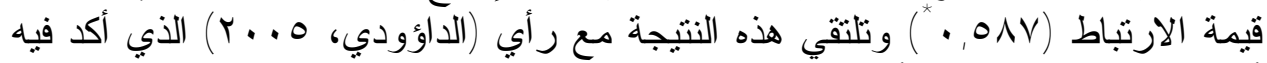

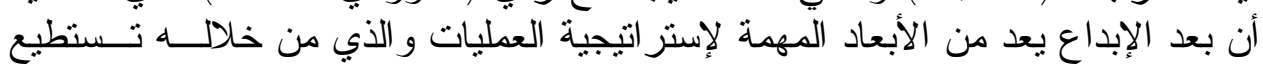

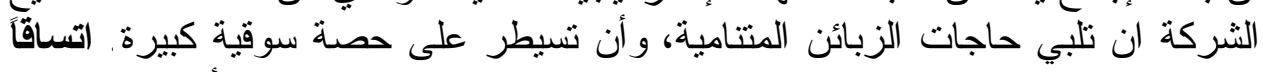

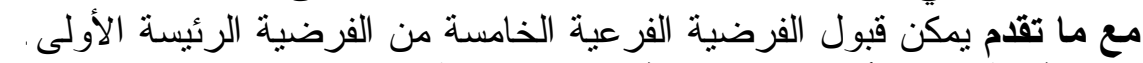

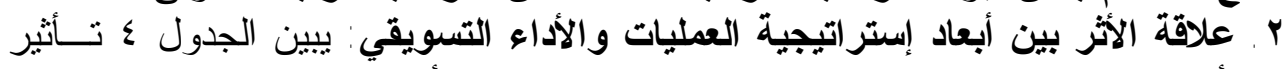

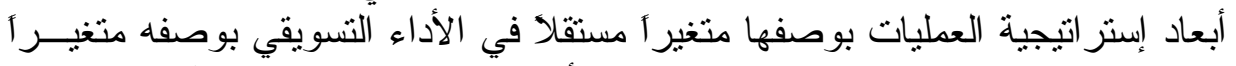

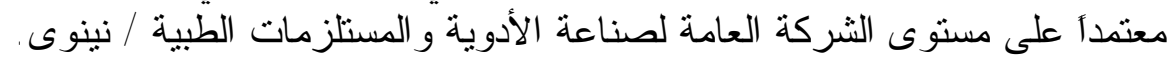

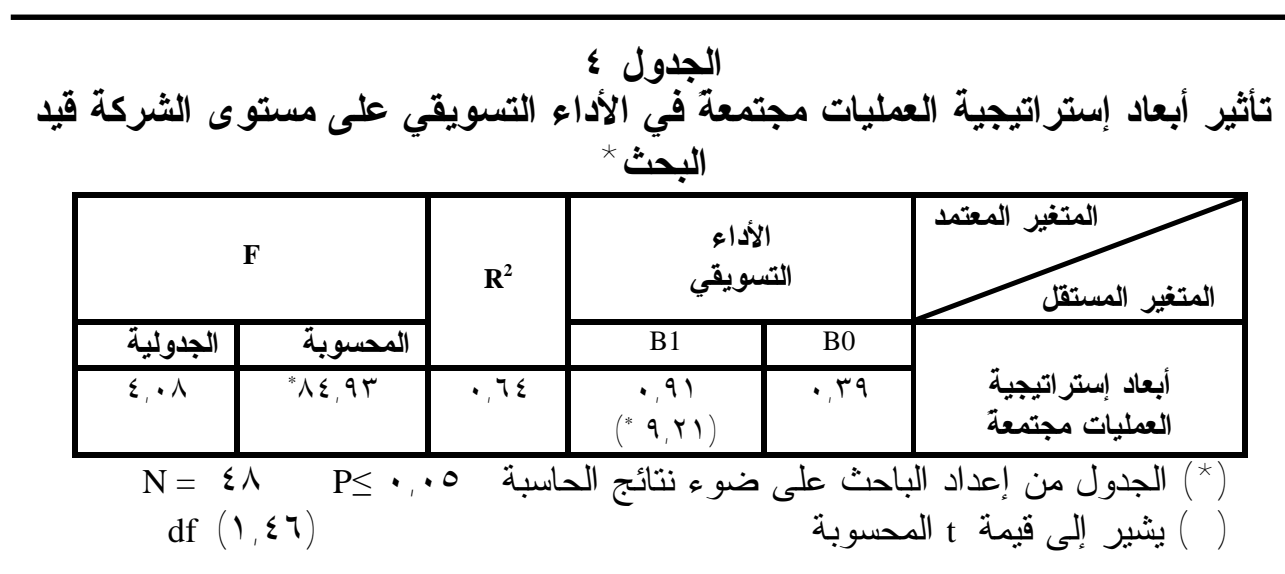

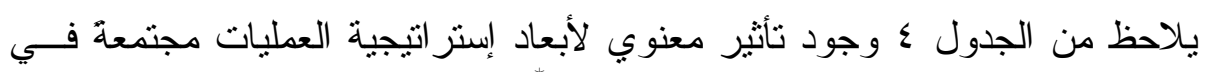

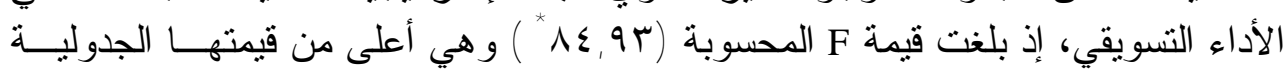




\section{[الكيكي}

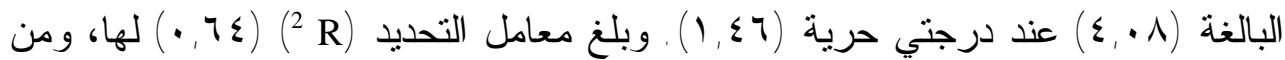

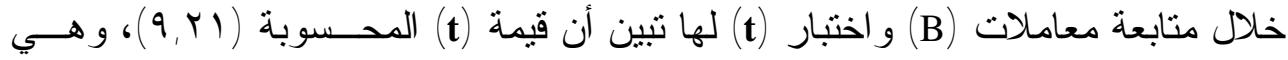

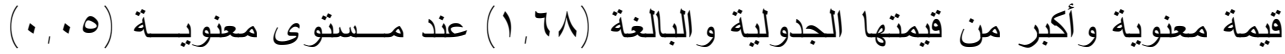

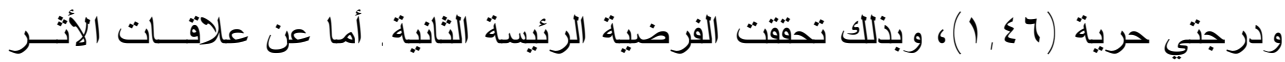

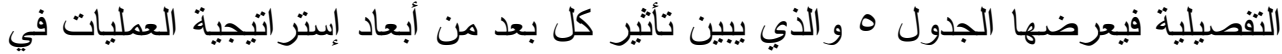
مؤشر ات الأداء التسويقي وعلى النحو الأتي :

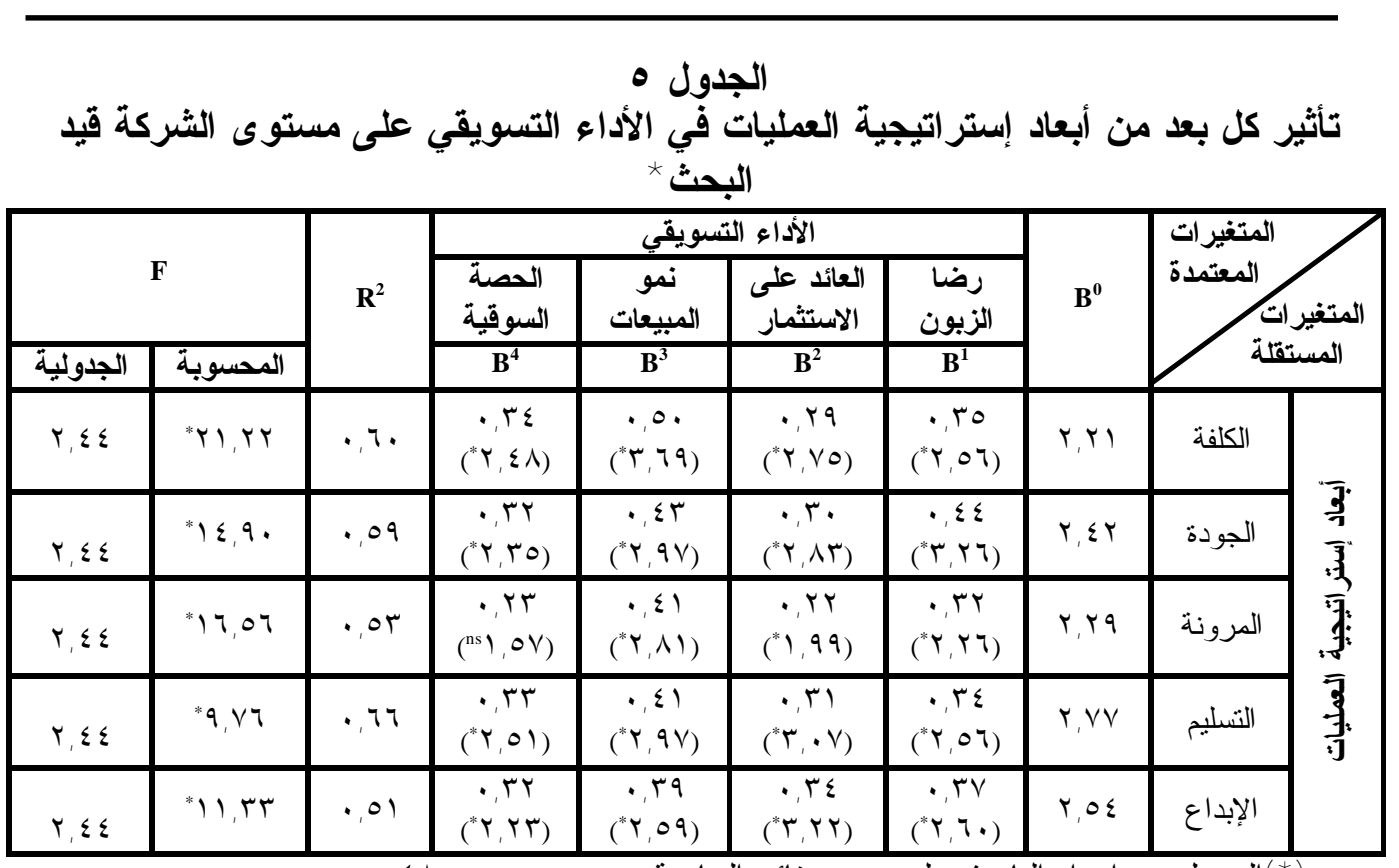

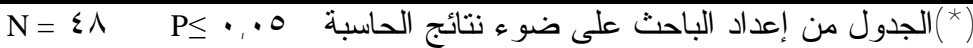
df $(0, \varepsilon Y)$

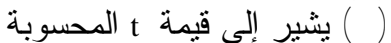

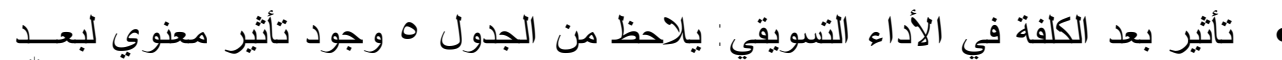

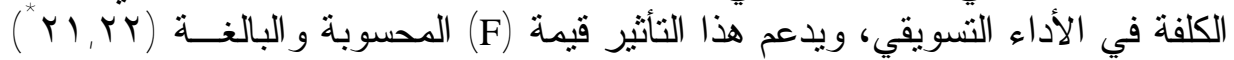

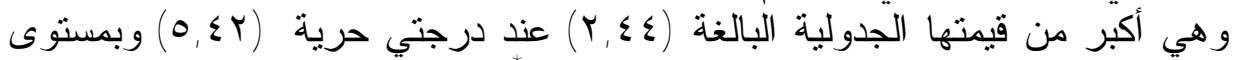

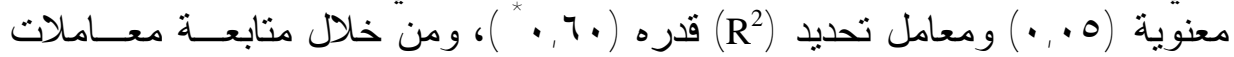

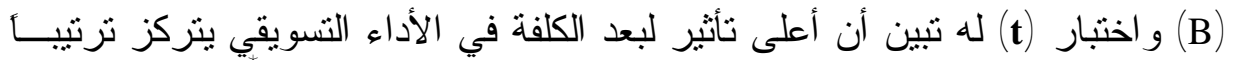

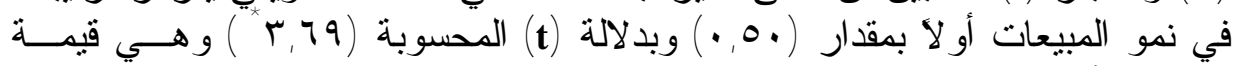

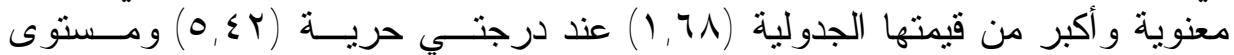

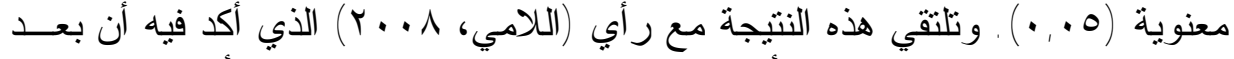

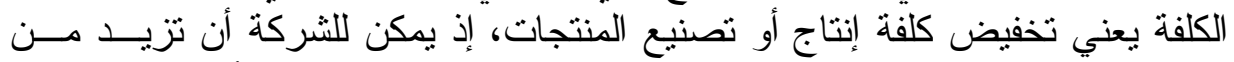

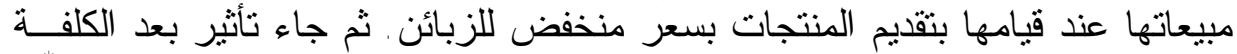

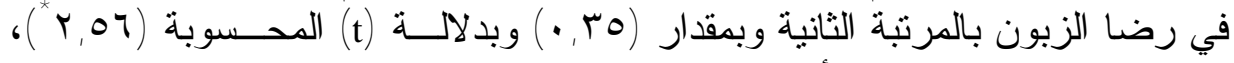

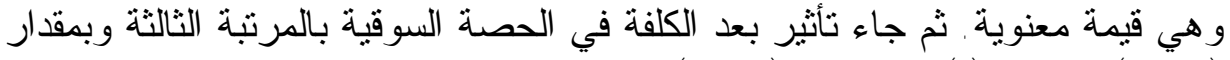

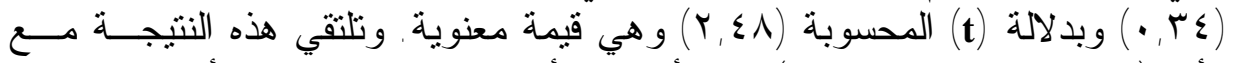

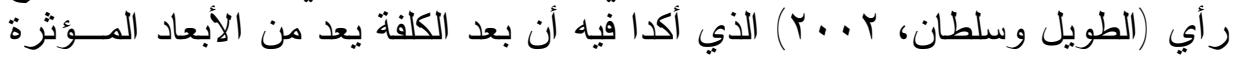




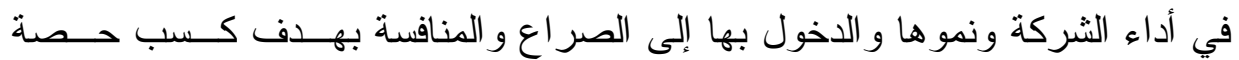

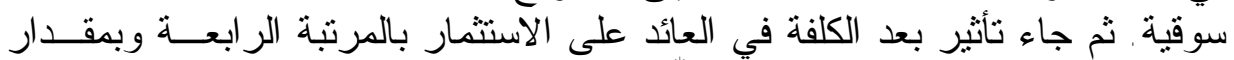

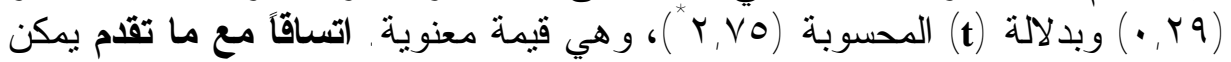

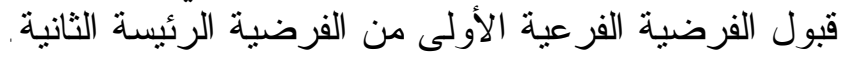

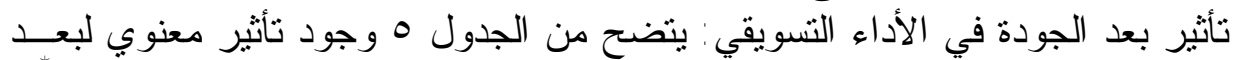

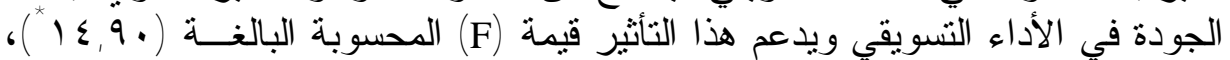

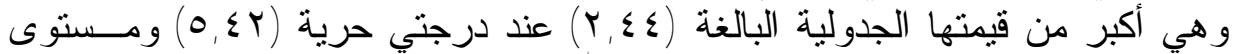

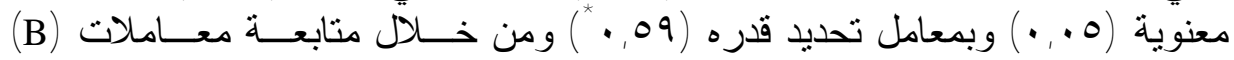

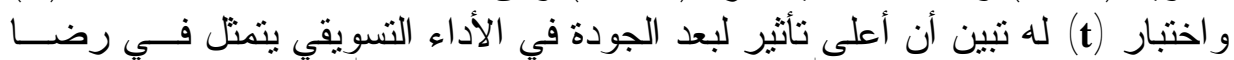

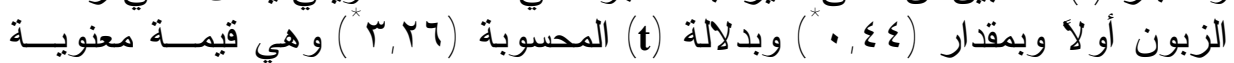

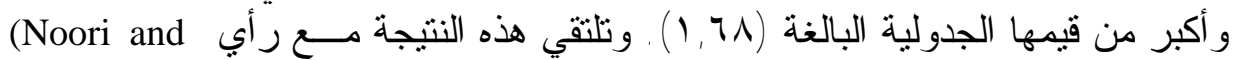

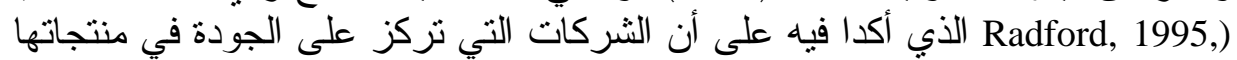

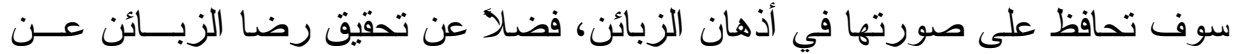

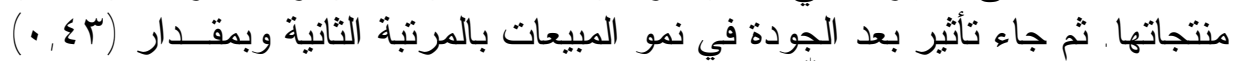

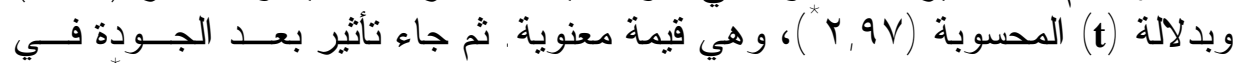

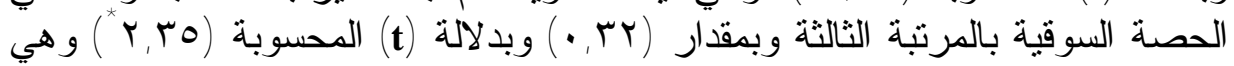

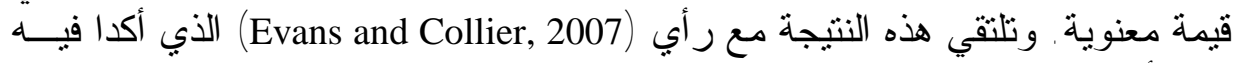

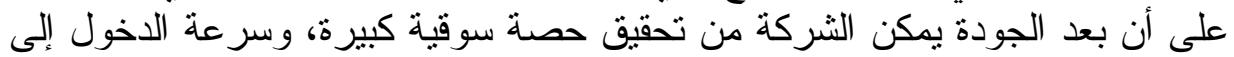

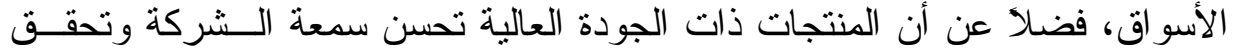

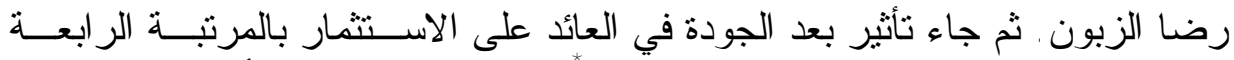

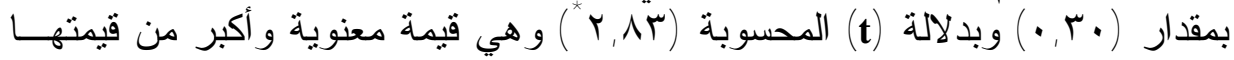

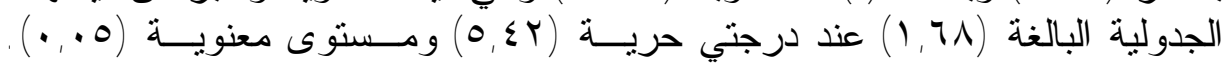

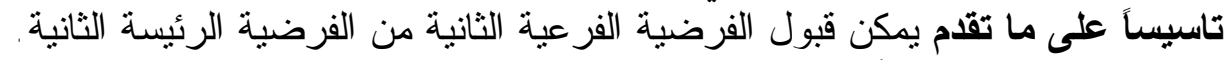

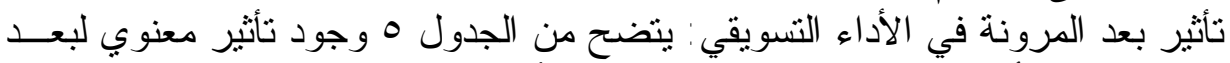

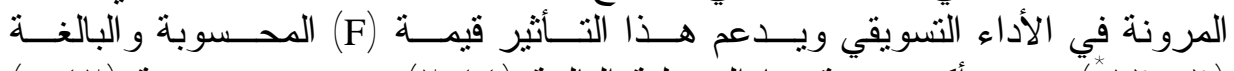

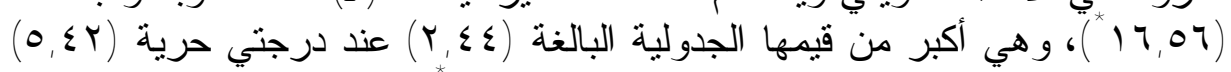

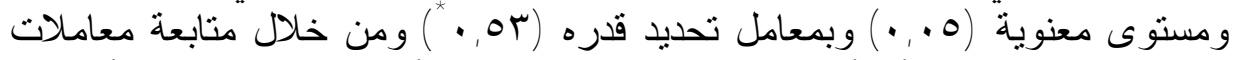

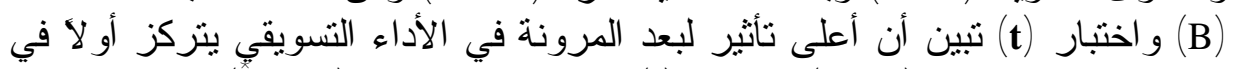

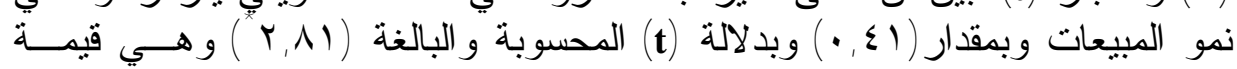

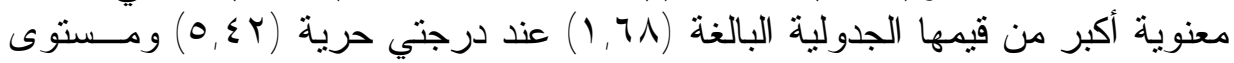

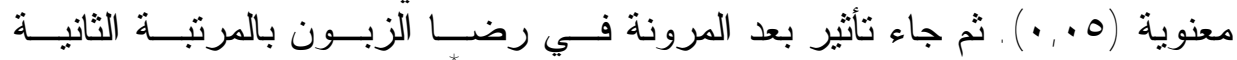

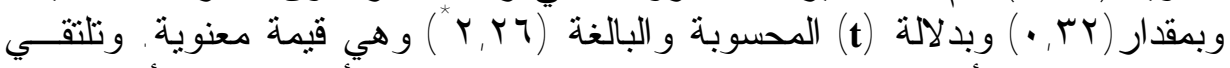

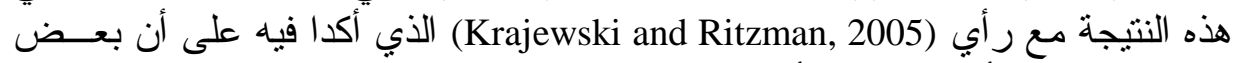

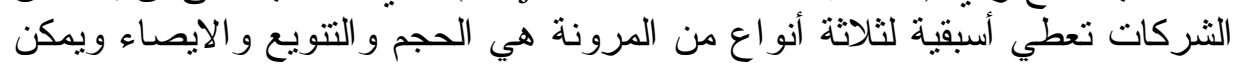

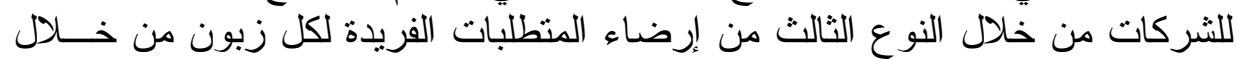

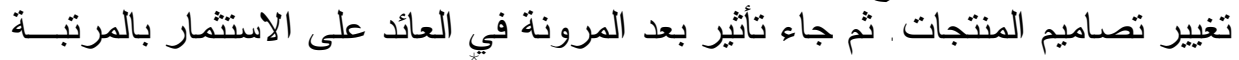

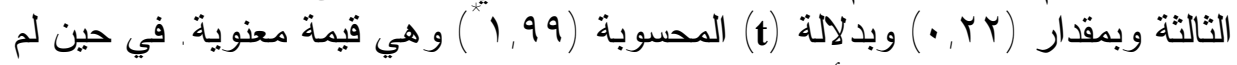

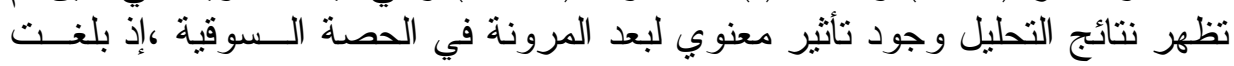




\section{الكيكي [9 ؛}

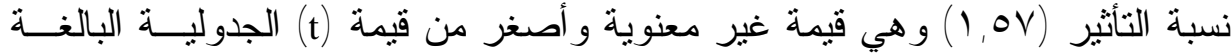

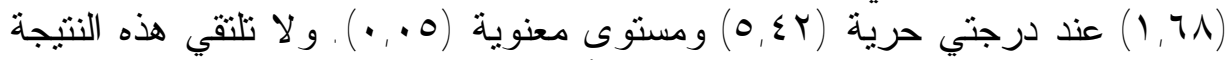

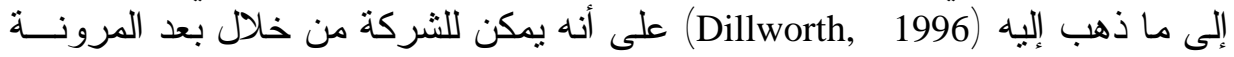

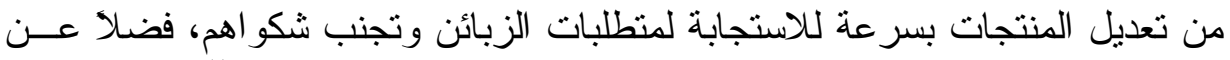

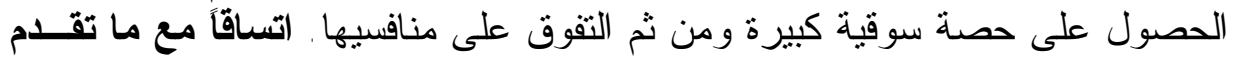
يمكن قبول الفرضية الفرعية الثالثة من الفرضية الرئيسة الثانية.

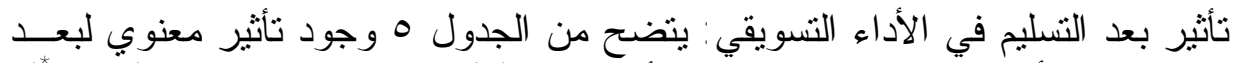

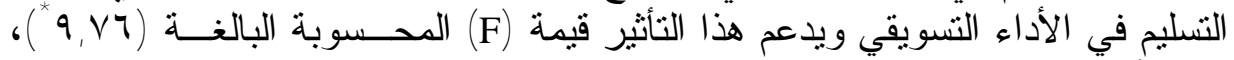

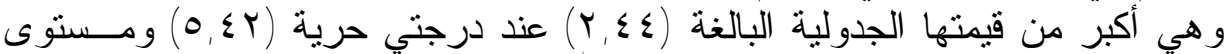

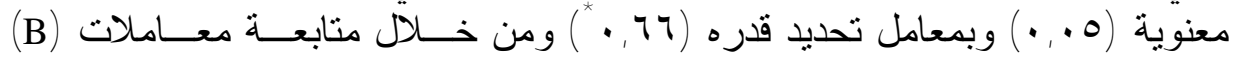

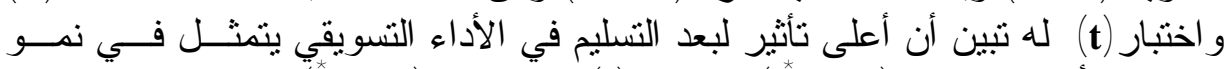

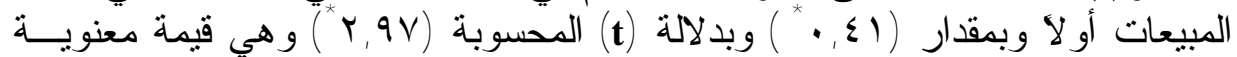

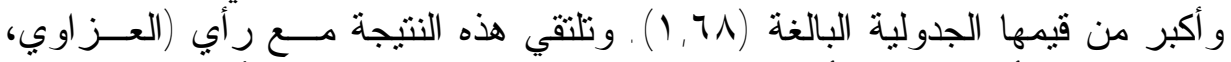

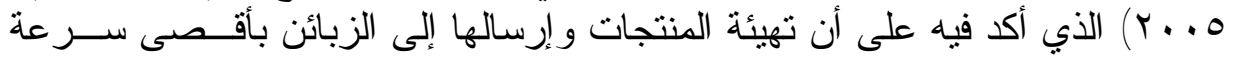

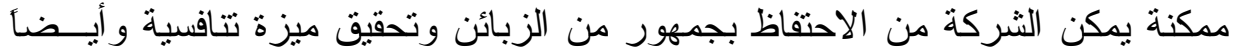

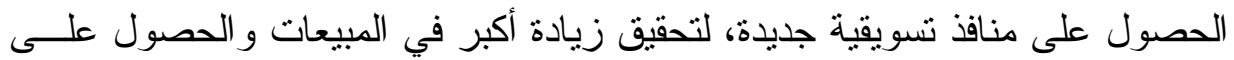

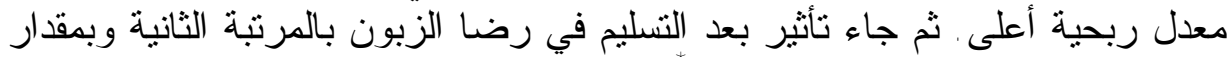

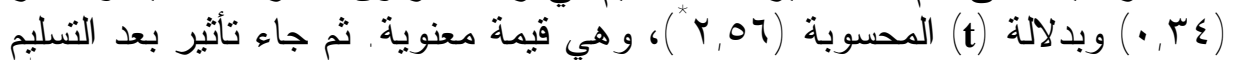

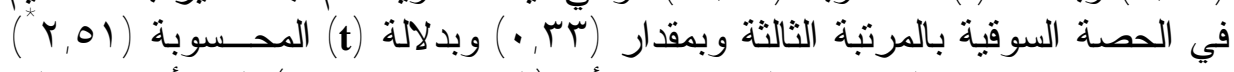

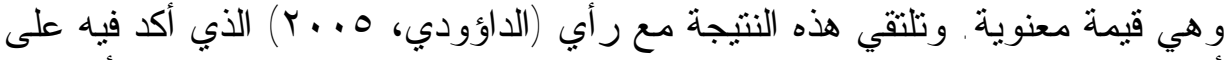

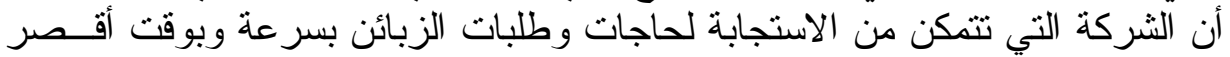

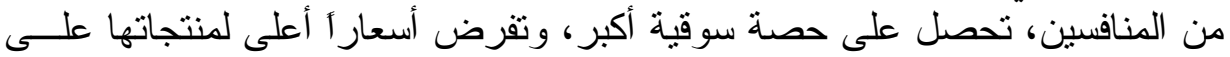

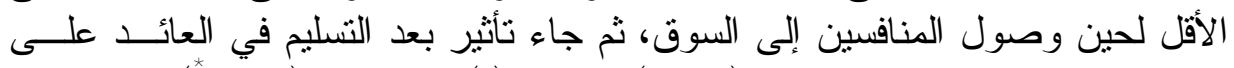

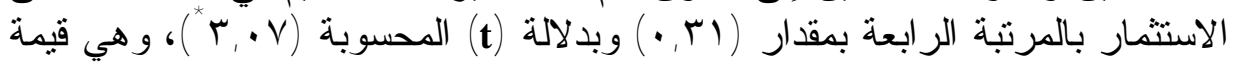

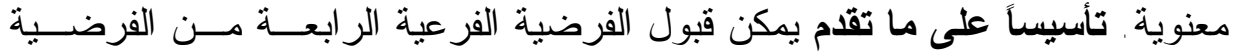
الرئيسة الثانية.

تأثثر بعد الإبداع في الأداء التسويقي: يلاحظ من الجدول ه وجود نأثير معنوي لبعـد

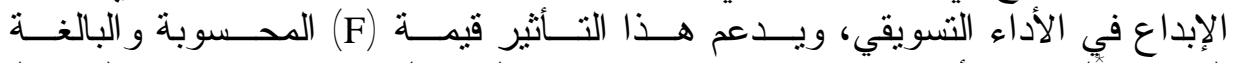

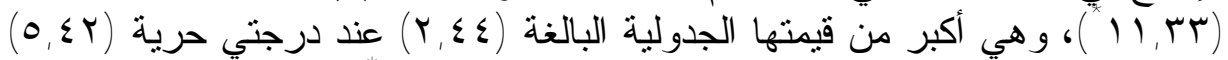

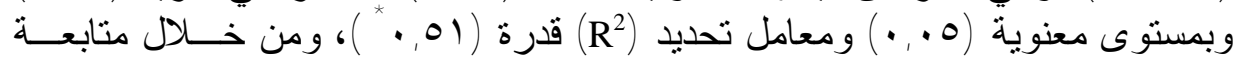

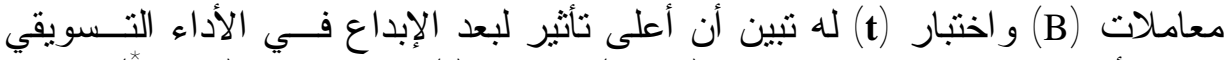
يتركز أو لا في نمو المبيعات بمقدار (

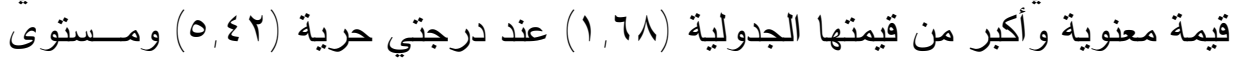

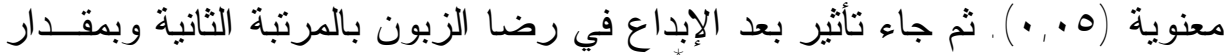

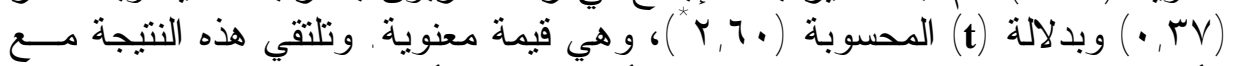

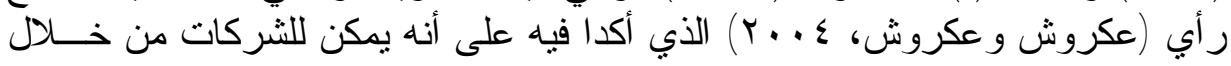

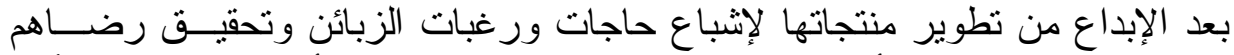

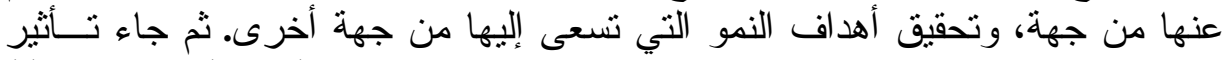

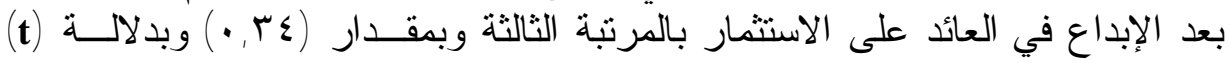




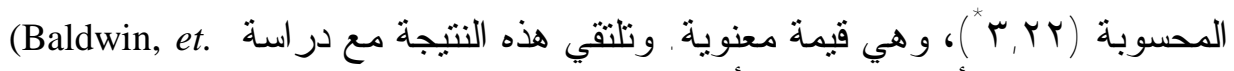

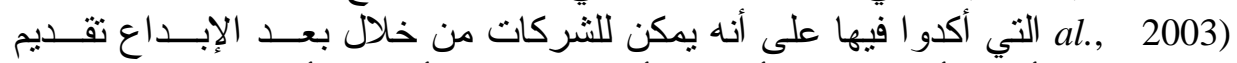

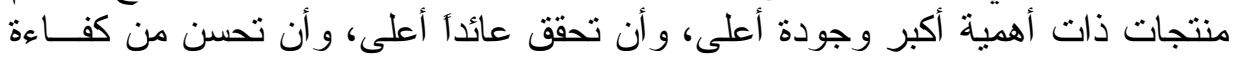

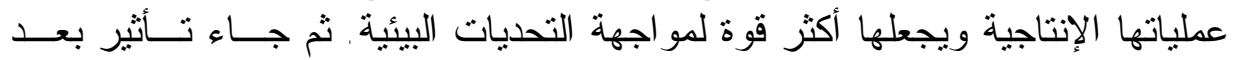

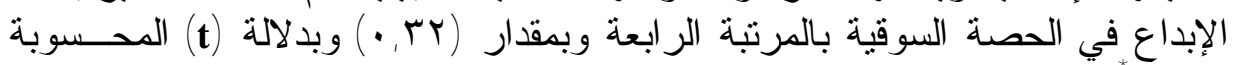

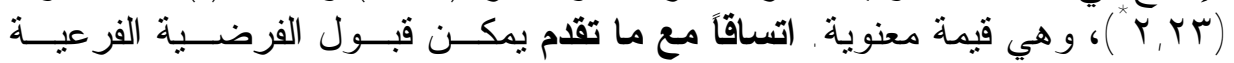
الخامسة من الفرضية الرئيسة الثانية.

$$
\begin{aligned}
& \text { الاستتتاجات و المقترحات } \\
& \text { أولاً - الاستنتاجات والماتر }
\end{aligned}
$$

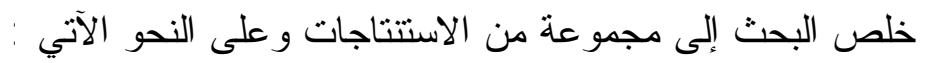

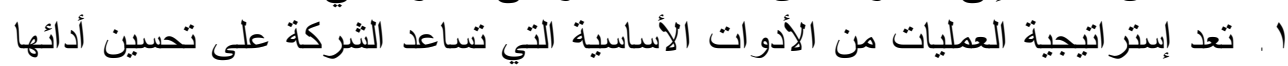

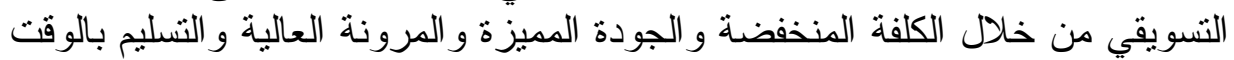

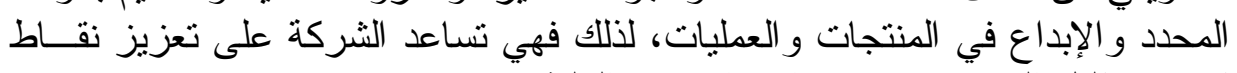
قوتها وتذليل المصأعب والعي ودعم إستر اتيجيتها الكلية.

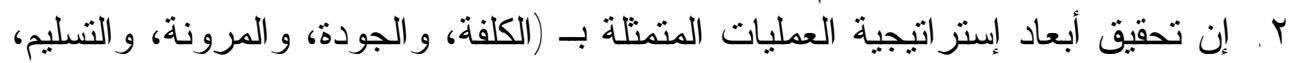

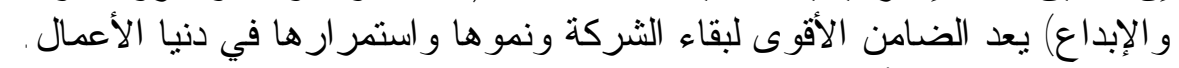

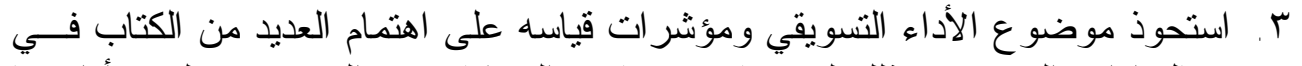

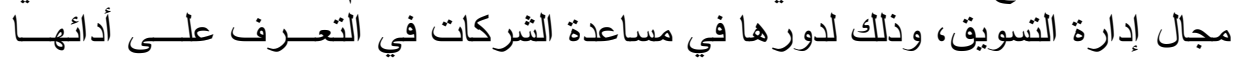

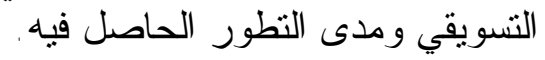

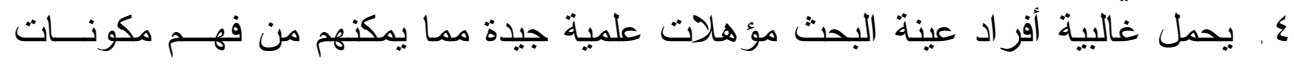

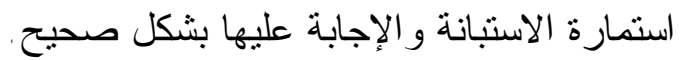

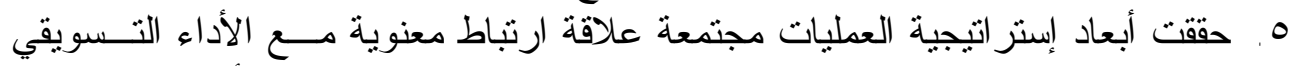

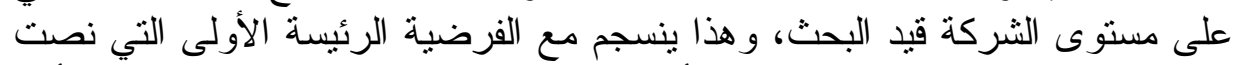

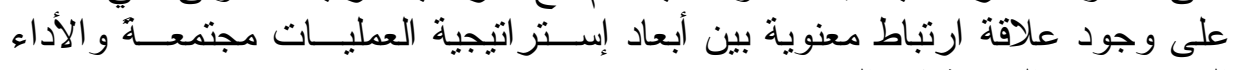

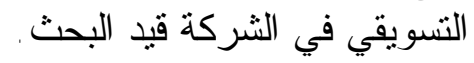
7 . . حقق كل بعد من أبعاد إستر اتيجية العمليات علاقة ارتباط معنوية مع الأداء التـسويقي

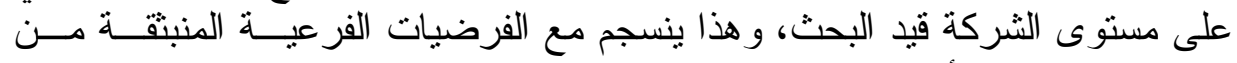

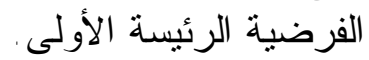

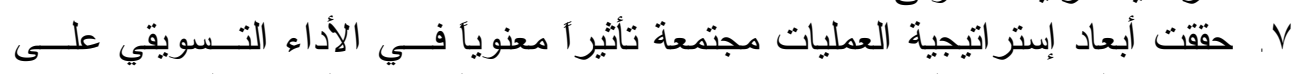

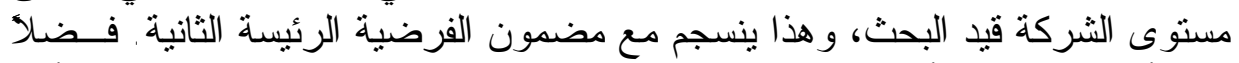

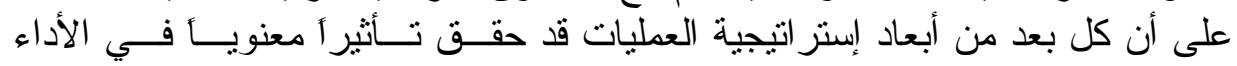

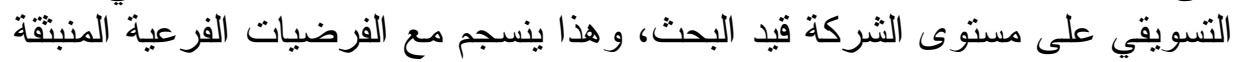
من الفرضية الرئيسة الثانية.

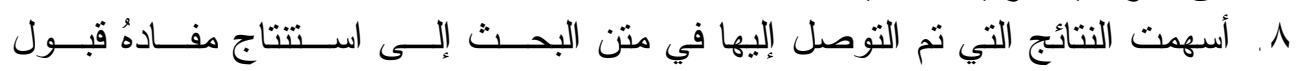
الفرضيات الرئيسة و الفرضيات الفرعية المنبنقة عنها في الثركة الثيد فيد البحث. 


\section{الكيكي[0 10 (20)}

$$
\text { ثانياً - المقترحات }
$$

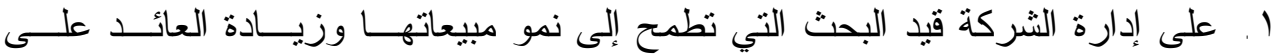

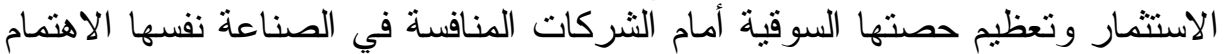

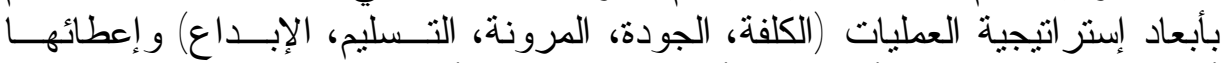
أهمية كبيرة لما لها من أثر كبير الثيات وأساسي في تحسين أدائها التسويقي.

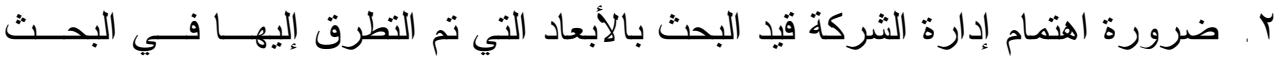

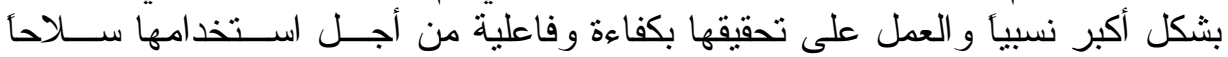

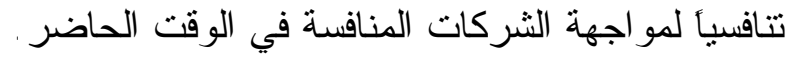

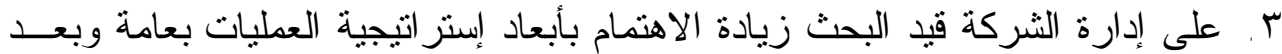

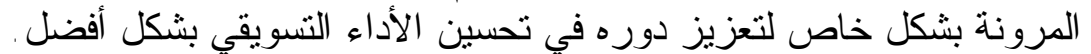

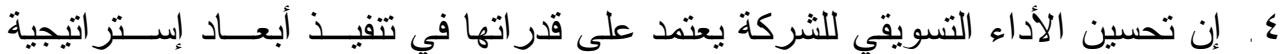

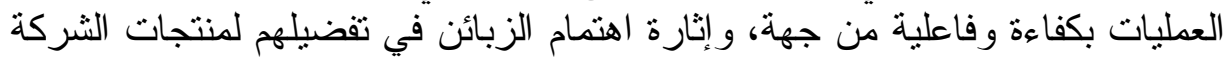
عن غير ها من منتجات الثركات المنافسة من جهة أنسة أخرى.

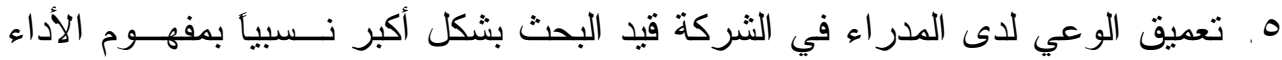

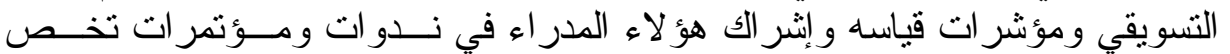

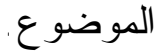
7 . . على إدارة الثركة قيد البحث زيادة الاهتمام بالأداء التشويقي وقياسه وتحليلــهـ بــين

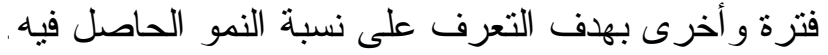

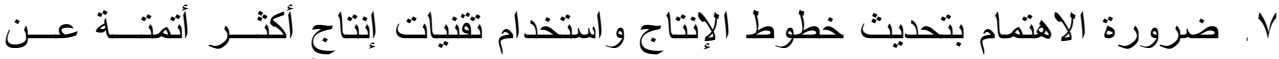

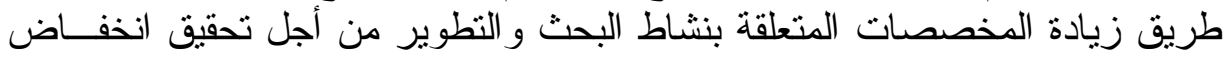
حقيقي في التكاليف التشغيلية ومو اكبة النطور ات التقنية.

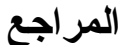 \\ أولاً - المر اجع باللغة العربية}

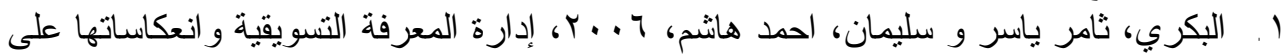

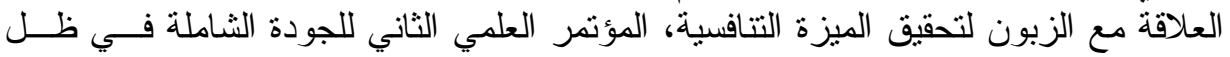
اقتصاديات المعرفة وتكنولوجيات المعلومات، كلية الاقتصاد و العلوم الإدارية، جامعة العادية العلوم التطبيقية الأردنية،عمان، الأردن.

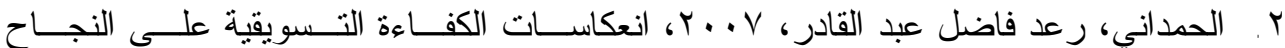

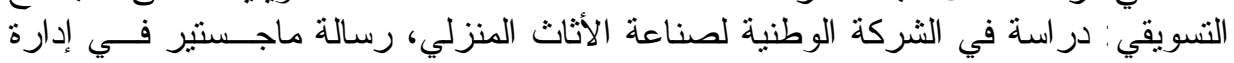

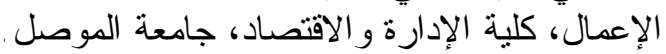

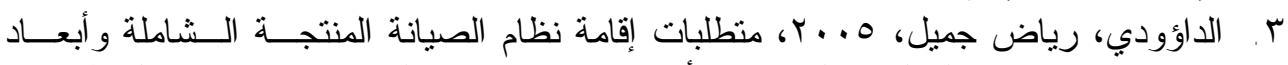

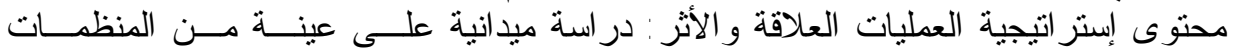
الصناعية في محافظة نينوى، رسالة ماجستير في الإدارة الصناعية، كلية الإدارة و الاقتصاد، التهاء

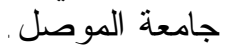

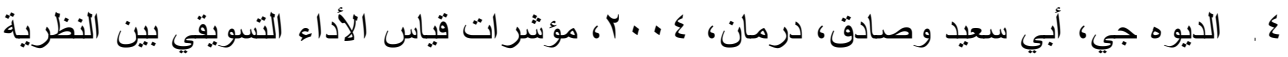

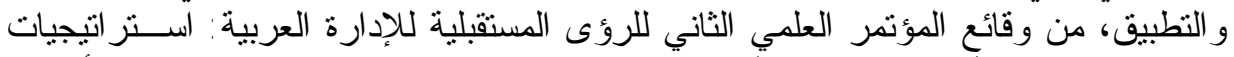

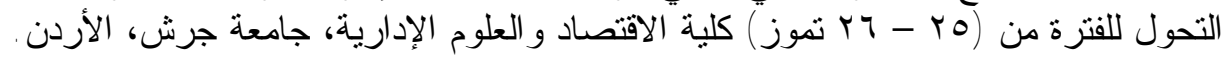




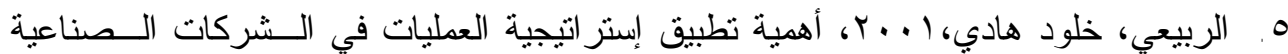

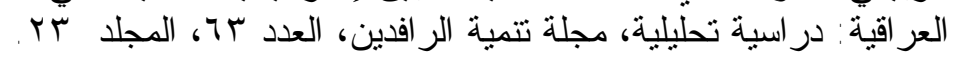

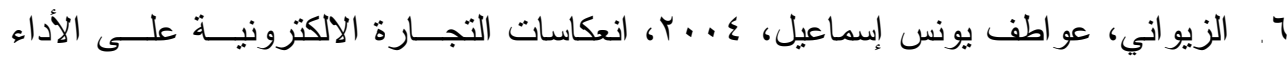

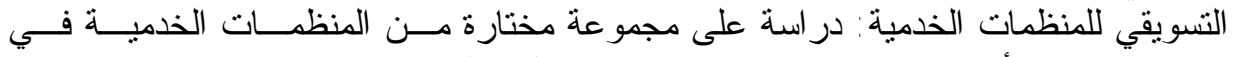

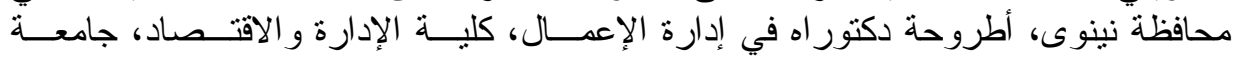

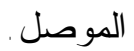

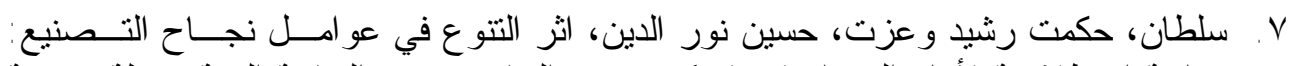

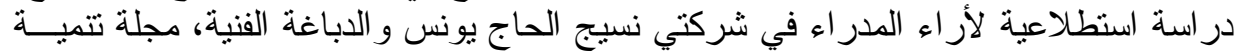

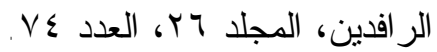

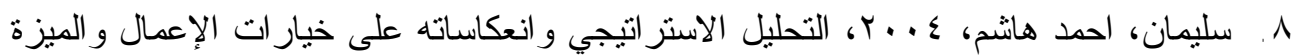

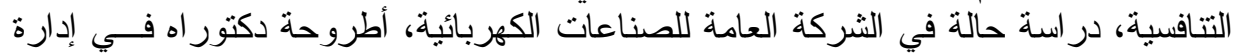

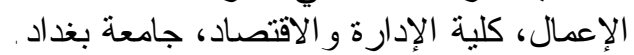

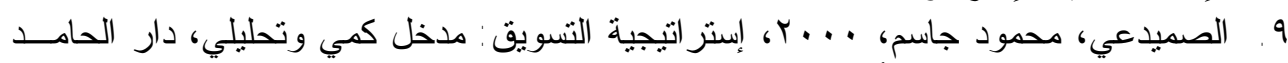

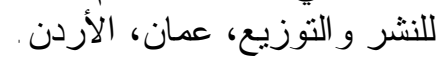

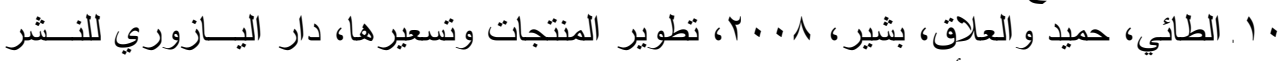

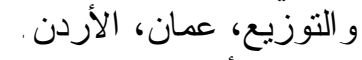

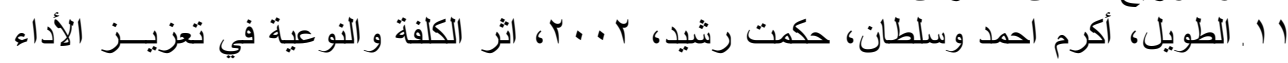

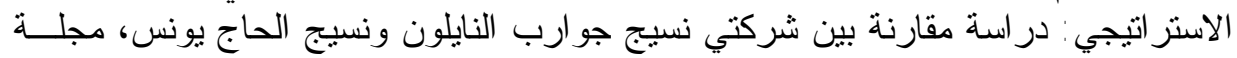

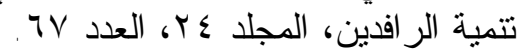

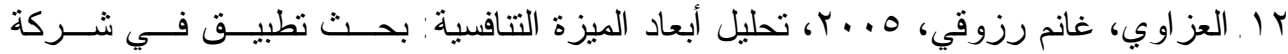

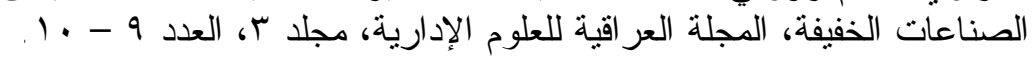

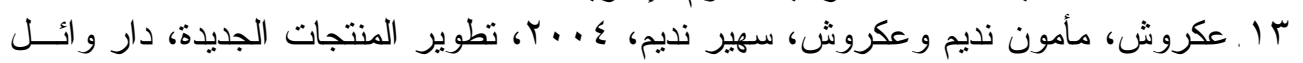

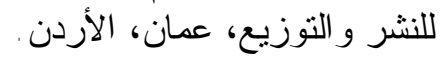

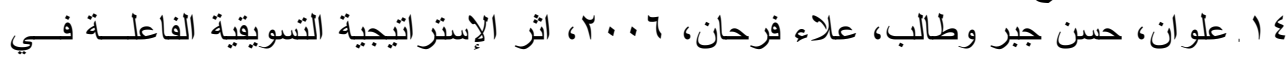

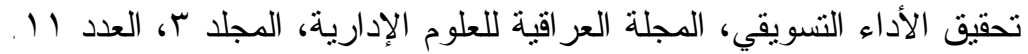

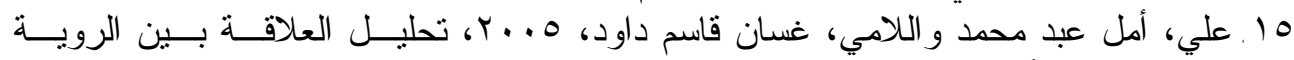

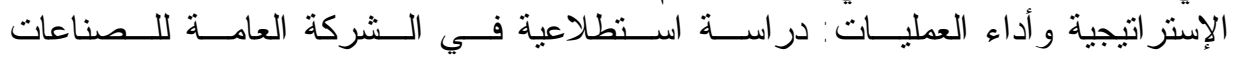

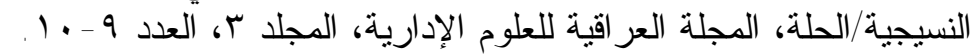

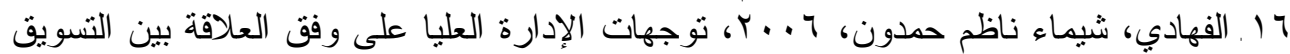

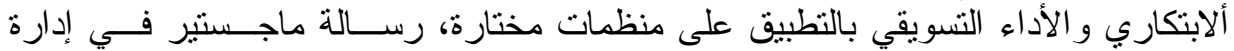

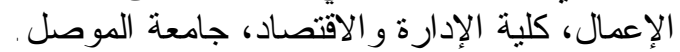

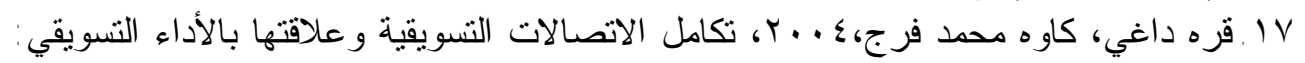

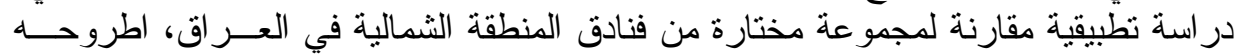
دكتور اه في إدارة الإعمال، كلية الإدارة و الإقتصاد، جانة جامعة المستتصرية.

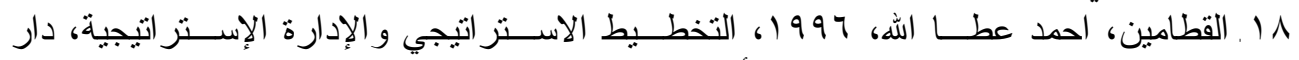

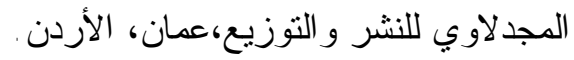

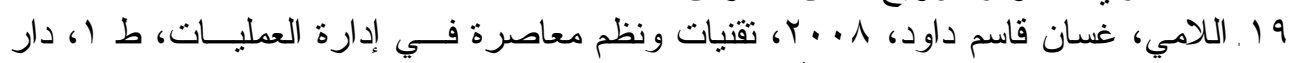

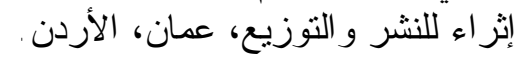

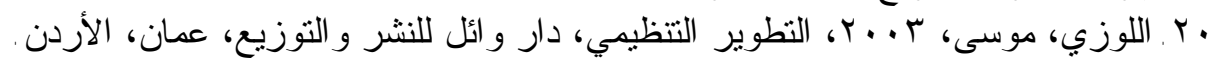




\section{الكيكي[0ron}

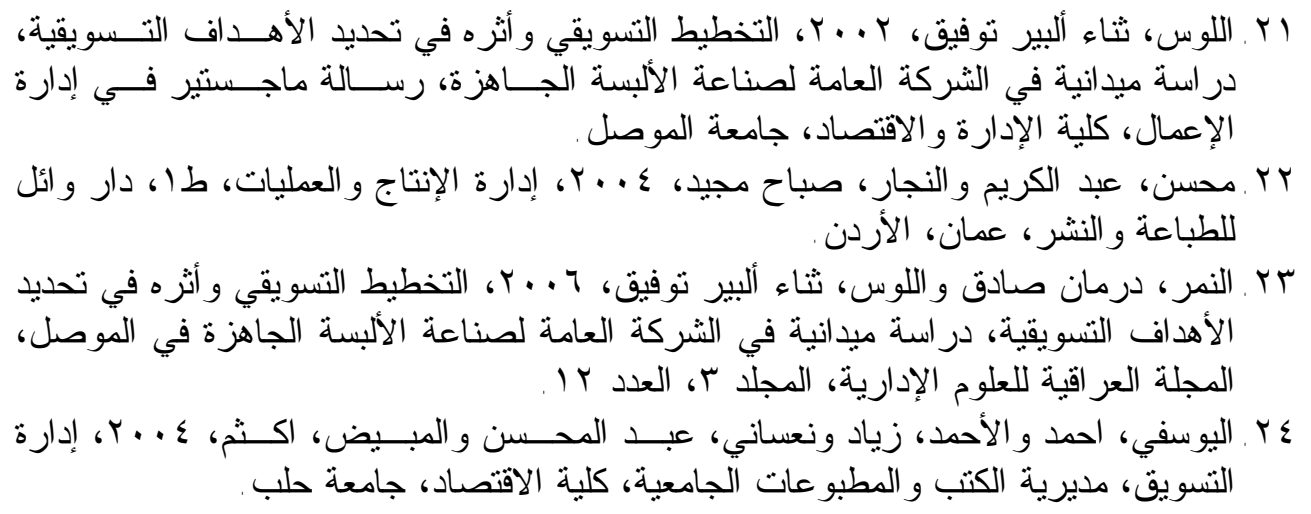

ثانياً - المر اجع باللغة الأجنبية

1. Baldwin, Nick and Crawford, Robert and Cridland, John, 2003, Competing in the Global Economy: the Innovation Challenge, httpwww.berr.gov.ukfilesfile12093.pdf.

2. Chase, Richard and Aquilano, Nicholas J and Jacobs, Robert, 2007, Operations Management for Competitive Advantage, $11^{\text {th }}$.ed, Mc Graw-Hill companies, Inc, Boston.

3. Dilworth, James, 1996, Operations Management, $2^{\text {nd }} . e d$, McGraw-Hill, Inc, U.S.A.

4. Davis, Mark M and Aquilano, Nicholas J and Chase, Richard and 2003, Fundamentals of Operations Management, $4^{\text {th }}$.ed, Mc Graw-Hill Higher Education, Boston.

5. Evans, James R and Collier, David A, 2007, Operations Management, Thomson South Western ,U.S.A.

6. Evans, Joel R, and Berman, Barry, 1997, Marketing, $7^{\text {th }}$.ed, prentice - Hall, Inc, N. J.

7. Fakhredaei, Navid, 2006, The Factors Affecting Adoption of CRM at the Organizational Level in Iran's Shipping Industry, http://epubl.ltu.se/16530187/2007/025/LTU-PB-EX-07025-SE.pdf .

8. Fredberg, Tobias and Elmquist, Maria and Ollila, Susanne, 2008, Managing Open Innovation -Present Findings and Future Directions.

httpwww.vinnova.seupload EPiStorePDFvr-08-02.pdf .

9. Heizer, Jay, and Render, Barry, 1999, Principles of Operations Management, $3^{\text {rd }}$. ed, prentice - Hall, Inc, New Jersey.

10. Hunger, David J and Wheelen, Thomas L, 1998, Strategic Management, $6^{\text {th }}$ ed, Addison Wesley Longmon Inc, New York.

11. Hafez, Naeim, 2006, Marketing, Arab and Foreign Perspectives, Arab Administrative Development Organization, Egypt.

12. Krajewski, Lee J. and. Ritzman, Larry P, 2005, Operations Management, $7^{\text {th }}$.ed, prentice - Hall , Inc, New Jersey.

13. Kotler, Philip, and Armstrong, Gary, 2001, Principles of Marketing, $9^{\text {th }}$ ed, prentice Hill, Inc, New Jersey.

14. Kotler, Philip, 2003, Marketing Management, prentice-Hall, Inc, N.J.

15. Lamb, Charles W and Hair, Joseph F and McDaniel, Carl. 1998, Marketing, $4^{\text {th }}$. ed, South - Western College Publishing, Ohio .

16. Noori, Hamid and Radford, Russell, 1995, Production and Operations Management, International Edition, McGraw-Hill Inc, U . S .A.

17. Perreault, William D and McCarthy, Jerome, 2000, Essentials of Marketing, $8^{\text {th }}$.ed., McGraw-Hill Higher Education, Boston.

18. Russell, Roberts and Taylor, Bernard W., 2000, Operations Management, 3rd ed. Prentice - Hall, Inc, New York . 
19. Ronkainen, Iikka and Rosenbloom, Bert and Sheth, Jagdish and et .al., 2003, Marketing, 2nd ed, Thomson South - Western ,Canada .

20. Slack, Nigel, and Chambers, Stuart, and Johnston, Robent, 2004, Operations Management, $4^{\text {th }}$.ed, prentice - Hall, New York.

21. Schroeder, Roger G, 2007, Operations Management, $3^{\text {rd }}$.ed, Mc Graw-Hill companies, Inc, Boston.

22. Zeithaml, Valarie A and Bitner, Mary, Services Marketing, 2000, Mc Graw-Hill Higher Education, Boston. 